\title{
The Student Experience of University Armed Service Unit Participation
}

In this chapter, we bring together the key findings from the survey of student participants in USUs, undertaken in spring 2013, in order to capture quantitative and qualitative data on the value of the USUs from the perspective of student participants. The questionnaire is reproduced in Appendix 1, and details on the distribution and analysis of the survey are given in section 2.2.1 above. A total of 1,798 responses were received. Of these, 842 identified as being in the OTC, 656 in the UAS and 285 in the URNU. ${ }^{54}$ In this chapter we explore the results of the survey in terms of the demographics of the units, the university and educational profile of the sample, motivations for joining a USU, the role of USU participation in skills development, student perceptions of the effect of USU participation on progression through university, the influence of participation on student career choices including careers in the armed forces, student understandings of the potential utility of the USU experience in seeking and gaining employment after graduation, student opinions about the armed forces on the basis of their USU participation and overall student assessments of their USU experience. Key findings are highlighted in the concluding section, and the wider implications of these are discussed in the concluding chapter.

In the following analysis of the survey results, all calculations have been made on the basis of total completed responses to a specific question, and all percentages have been rounded to the nearest whole number. We have not

${ }^{54}$ As noted in Chapter 2, some respondents did not complete all the questions. For example, 15 respondents failed to identify which service unit they were members of.

How to cite this book chapter:

Woodward, R, Jenkings, K N and Williams, A J. 2015. The Value of the University Armed Service Units. Pp. 45-100. London: Ubiquity Press. DOI: http://dx.doi. org/10.5334/baq.c. License: CC-BY 4.0. 
attempted to disaggregate responses within each service unit because of variations in response rates between units within each service.

\subsection{Demographic characteristics of the university armed forces units survey sample}

\subsubsection{Age}

The age profile of the sample, shown in Figure 3.1, reflects the expected profile for UK undergraduate students. On average, just under three quarters of the participants were aged 19, 20 or 21 on $31^{\text {st }}$ March 2013.

\subsubsection{Gender}

Although across the total UK student population slightly more women than men participate in higher education, Figure 3.2 confirms an anticipated finding: that fewer women are USU participants. Across the sample, URNUs had the highest proportion of women of the three service units, and OTCs had the lowest.

\subsubsection{Educational background}

Respondents were asked about their educational background pre-university, because of significant anecdotal evidence which suggested that USUs attract a higher proportion of students who were educated in the independent (feepaying) school sector than both the national average, and the average for their particular university. Figure 3.3 shows the proportion of USU participants, both

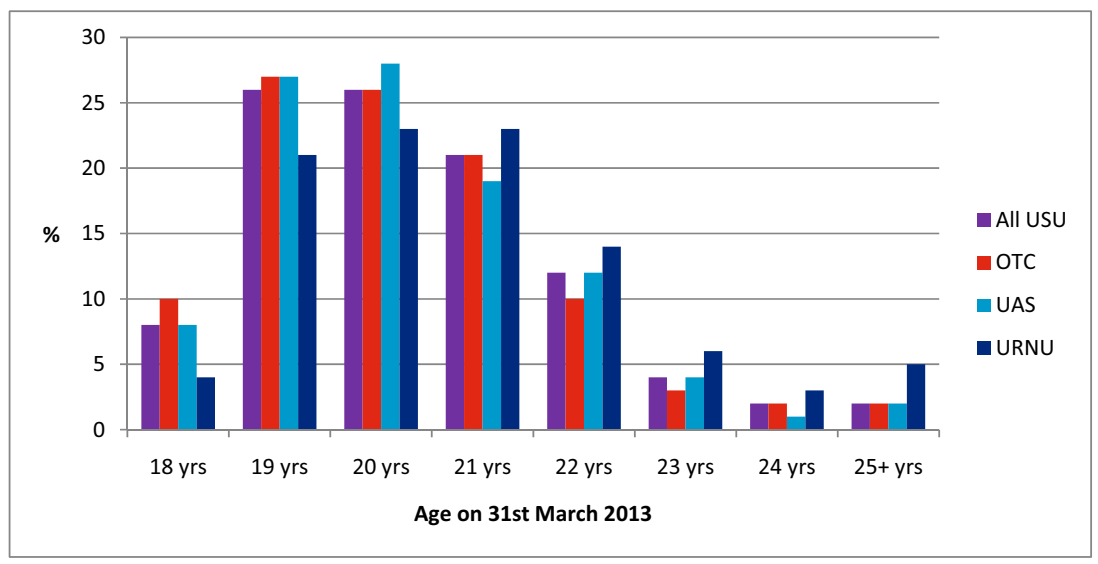

Figure 3.1: Age profile of USU survey participants, by percentage. 


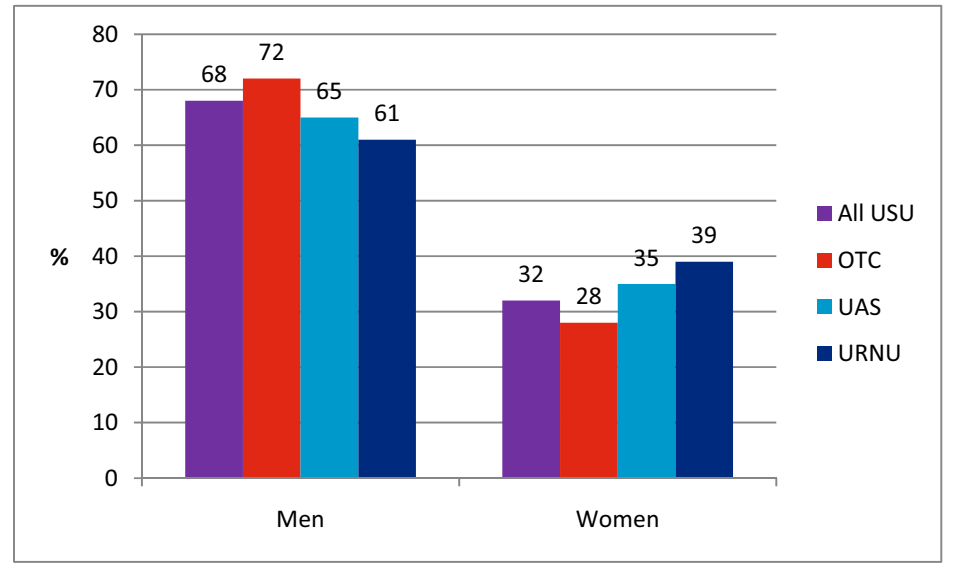

Figure 3.2: Gender profile of USUs sample, by percentage.

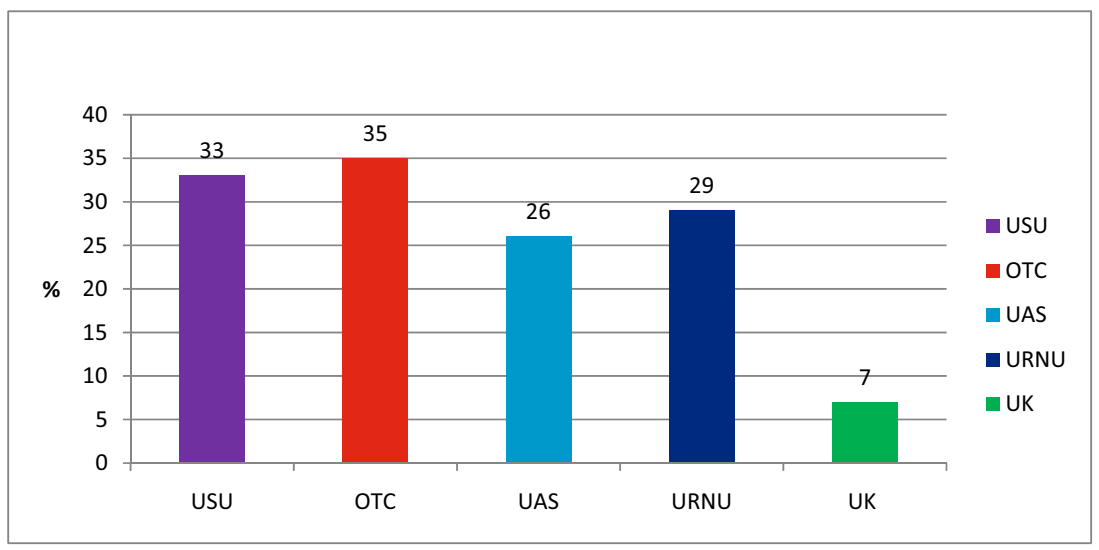

Figure 3.3: Proportion of sample attending independent school, by percentage.

overall and by service unit, who attended an independent sector (fee-paying) school or college (including both boarders and day pupils) whilst studying for A levels or equivalent.

The UK average for pupils attending schools in the independent sector for A level (or equivalent) education is about $7 \% .{ }^{55}$ As the survey data shows, the proportion in each USU from this educational background prior to university is far higher than the national average. We were unable to compare educational

55 Social Mobility and Child Poverty Commission. (2014). Elitist Britain? Retrieved from https://www.gov.uk/government/publications/elitist-britain 
backgrounds by service units against averages for individual universities because of the differentials in response rates from individual units and thus specific universities. ${ }^{56}$ The disproportionate number of USU participants with an educational background in the independent sector raises wider points about the extent of the provision of the USUs across the higher education sector, and we discuss this in more detail in Chapter 7.

\subsubsection{Length of time in unit}

Figure 3.4 shows the length of time student respondents had spent in their units. There is a common picture across the three service units of a higher proportion having up to one year's experience. We have included this information here, as it may be useful in illuminating some of the experientially-based responses discussed later in this chapter. It also indicates quite clearly the different participation patterns across the three units, which include patterns of training according to service unit syllabi.

In conclusion, in terms of the demographic characteristics of the survey sample, we have made a working assumption for the analysis which follows that the sample is broadly representative of the service units as a whole, but that because response rates from some specific units were low, appropriate caution needs to be exercised in the interpretation of some survey results.

\subsection{University attendance, qualifications, degree subjects and other activities}

In this section we consider the type of university attended by our survey respondents, the qualifications and degree subjects for which they were registered and information about other activities undertaken at university.

\subsubsection{Representation across the higher education sector}

Student participation in USUs is uneven across the higher education sector. Anecdotally, it is widely recognised by those responsible for the USUs within the MoD and armed forces that the proportion of USU participants attending a Russell Group university is far higher than those attending from other mission group universities or types of institution, particularly from the post-1992 new universities. Overall, our survey showed that $53 \%$ of respondents attended a Russell Group university (which number 24), 14\% attended a University

\footnotetext{
${ }^{56}$ Note that it might be feasible to do this at a very crude level, given that universities routinely collect information about their entrants' educational backgrounds. Any meaningful comparison would require full coverage from across the USUs, something which we cannot claim to have in this survey.
} 


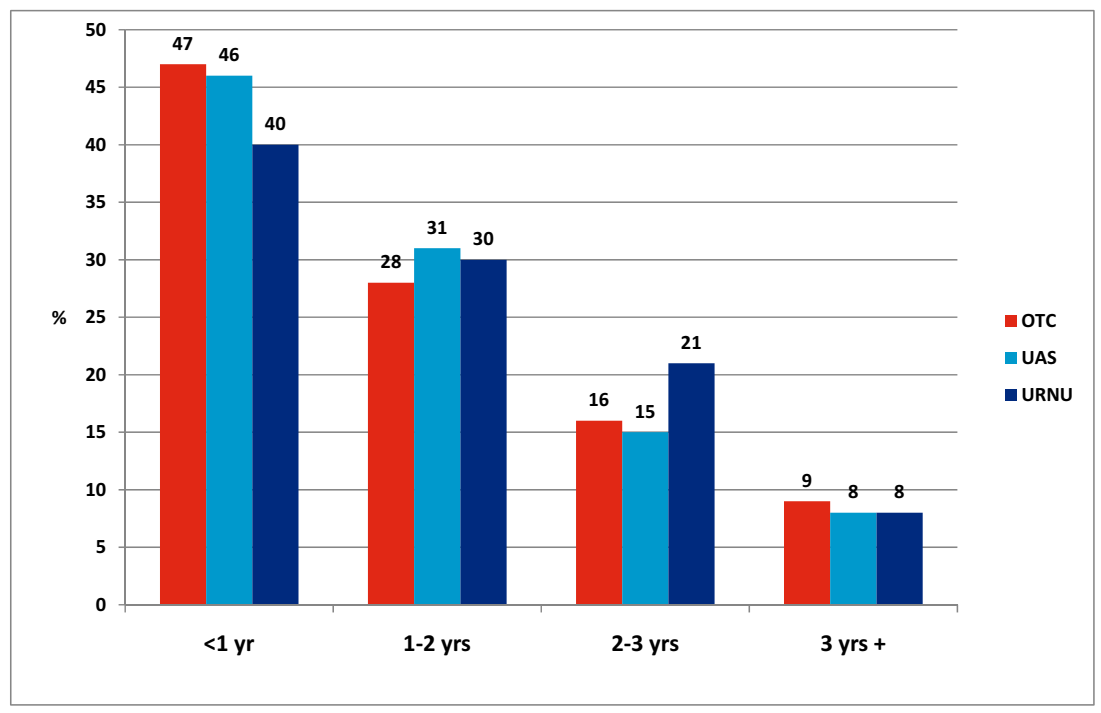

Figure 3.4: Length of time in unit at point of survey, by percentage.

Alliance institution (which number 20) and 2\% attended a GuildHE institution (which number 30). ${ }^{57}$

Yet the survey also gave a good indication of the reach (and thus potential reach) of the USUs across the whole university sector. A total of 108 higher education institutions were represented in terms of student responses in the survey, which included responses from all 46 USUs. Note that the UK national body representing universities across the higher education sector, Universities UK, has 133 members. The sample produced responses from OTC participants attending 82 different institutions, UAS participants from 83 different institutions and URNU participants at 54 institutions. The full list of institutions represented by student participants is given in Appendix 5. The key point here is about the reach of the USUs in terms of providing a potential opportunity for students across the higher education sector, and the limits to that reach in terms of actually drawing students in from across the sector. The data clearly shows that the USUs have reach beyond their traditional home in the established (primarily Russell Group) universities, and the limits to that reach. We discuss in Chapter 7 the wider issues the data on representation of the USUs and issues of reach raises for participation.

${ }^{57}$ Details on Russell Group membership are available at: http://www.russellgroup.ac.uk/ our-universities/. Details on University Alliance membership are available at: http://www. unialliance.ac.uk/member/. Details on GuildHE membership are available at: http://www. guildhe.ac.uk/members/ 


\subsubsection{University degree type and stage of joining the university armed service units}

A very common perception of the USUs is that they are the preserve of undergraduate students, particularly students in the first two years of study for a BA or BSc (undergraduate or Bachelors) university degree (typically of three years' duration in England, Wales and Northern Ireland, and four years' duration in Scotland). The data in Figure 3.5 supports this perception.

Reflecting the specialist training delivered in some universities in particular subjects (typically sciences, including engineering), included amongst the possible response choices to the survey question about degree type was a four-year degree leading to the award of a Masters qualification (such as an MEng.), and Figure 3.5 shows the differences between the service units in the proportion of members surveyed undertaking such degrees. The option of postgraduate diploma was also included as a potential option for response; only one URNU and one OTC participant selected this option, and these data are not included in Figure 3.5. The proportion registered for a $\mathrm{PhD}$ was very small. A point to note on the basis of the data in Figure 3.5 is the potential that the USU experience may offer for students across different stage cohorts to mix, something shared across many student activities but often very limited through degree programmes.

It is also commonly assumed that the majority of USU participants join in their first year of study, and the data shown in Figure 3.6 supports this.

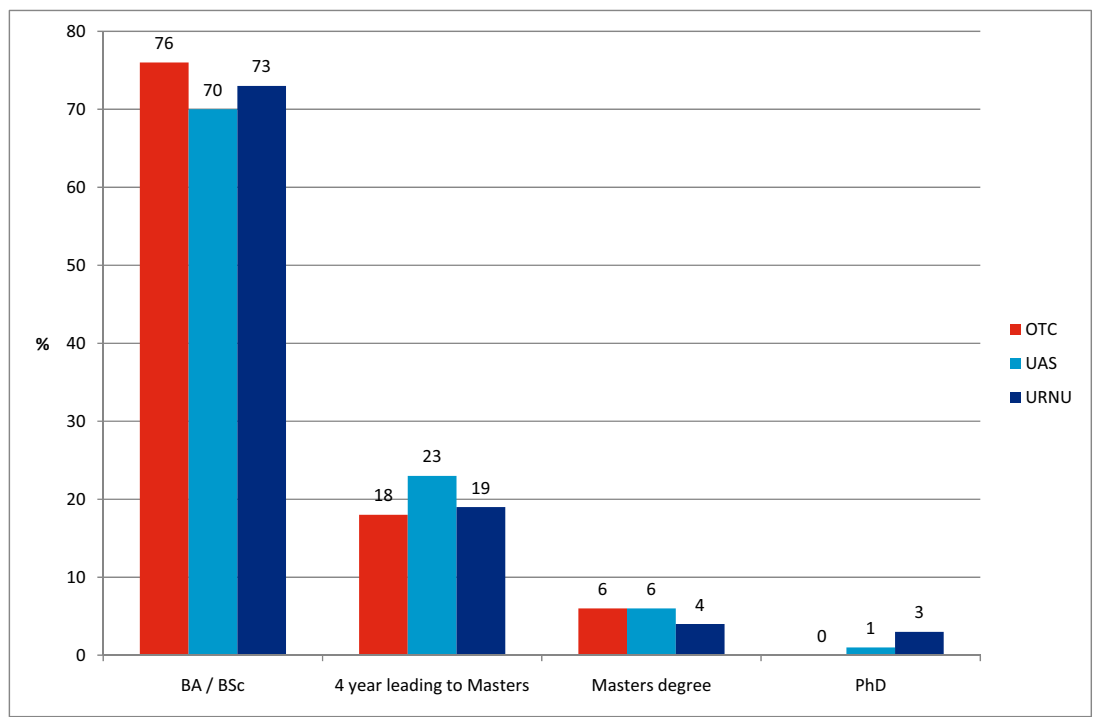

Figure 3.5: Proportion of USU participants by degree type, by percentage. 


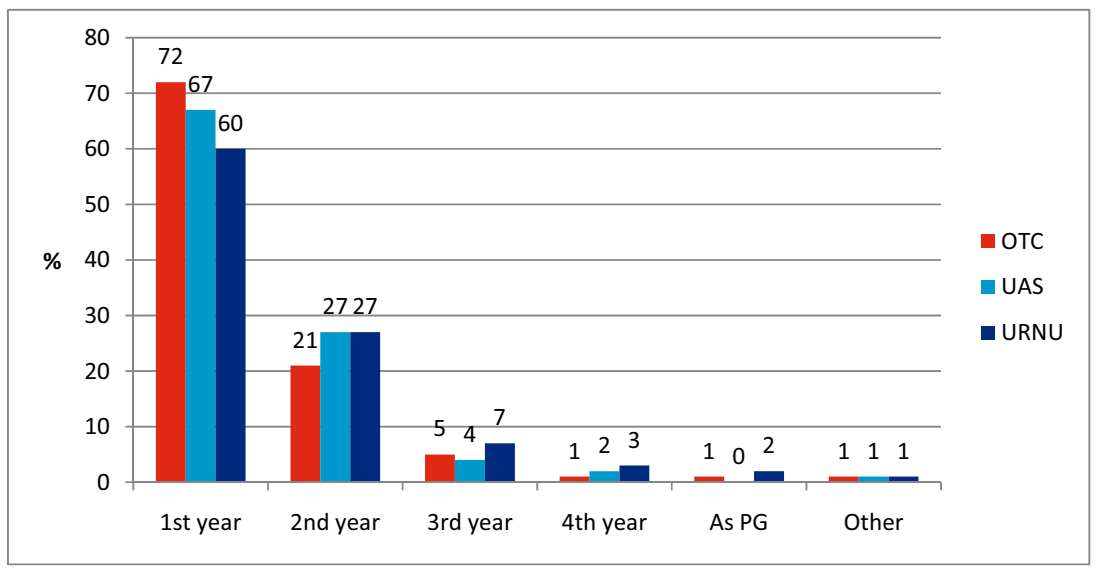

Figure 3.6: University stage on joining USU, by percentage.

Taking the data indicated in Figures 3.5 and 3.6 together, we can conclude both that participating in a USU is primarily an undergraduate activity, and one which for the majority commences in the first year of study, but also that this is not an absolute pattern. In terms of USU recruitment debates, two points follow from this. The first concerns the potential for expanded participation or more inclusive participation that may exist with a greater focus on students beyond the first year of undergraduate study at the point of joining. The second concerns the limits to participation amongst students in later stages of study (particularly at Masters level) because of the difficulties of combining academic and USU commitments.

\subsubsection{University armed service units participation and degree subject}

The USUs offer the experience of participation to university students regardless of subject studied and degree programme followed. We were interested to explore whether USU participation mapped on to particular degree subjects, and how any pattern of USU participation by degree subject corresponded to national patterns in the higher education sector. We asked survey respondents the title of their degree programme, and manually coded the data against Joint Academic Coding System (JACS) codes used by the Higher Education Statistics Agency (HESA) for all UK degree programmes. ${ }^{58}$ Table 3.1 and Figures 3.7, 3.8, 3.9 and 3.10 show the results of this analysis (with the figures omitting subject areas where USU participation was minimal or negligible).

${ }^{58}$ The Higher Education Statistics Agency JACS3 codes are available at: https://www.hesa. ac.uk/component/content/article?id=1787 


\begin{tabular}{|c|c|c|c|c|c|}
\hline & JACS subject area & OTC & UAS & URNU & National UK \\
\hline 1 & Medicine and dentistry & 5 & 10 & 11 & 3 \\
\hline 2 & Subjects allied to medicine & 4 & 2 & 5 & 12 \\
\hline 3 & Biological sciences & 14 & 11 & 11 & 9 \\
\hline 4 & Veterinary science & $<1$ & $<1$ & $<1$ & $<1$ \\
\hline 5 & Agriculture \& related subjects & $<1$ & $<1$ & $<1$ & 1 \\
\hline 6 & Physical sciences & 9 & 11 & 10 & 4 \\
\hline 7 & Mathematical sciences & 1 & 3 & 1 & 2 \\
\hline 8 & Computer science & 2 & 2 & 2 & 4 \\
\hline 9 & Engineering \& technology & 16 & 30 & 22 & 7 \\
\hline A & Architecture, building \& planning & 1 & $<1$ & 1 & 2 \\
\hline B & Social studies & 14 & 11 & 12 & 9 \\
\hline $\mathrm{C}$ & Law & 3 & 3 & 2 & 4 \\
\hline $\mathrm{D}$ & Business and administrative studies & 8 & 5 & 4 & 14 \\
\hline $\mathrm{E}$ & $\begin{array}{l}\text { Mass communications \& } \\
\text { documentation }\end{array}$ & $<1$ & $<1$ & 1 & 2 \\
\hline $\mathrm{F}$ & Languages & 4 & 2 & 5 & 5 \\
\hline G & Historical \& philosophical studies & 10 & 4 & 5 & 4 \\
\hline $\mathrm{H}$ & Creative arts \& design & 2 & 1 & $<1$ & 7 \\
\hline I & Education & $<1$ & $<1$ & $<1$ & 8 \\
\hline $\mathrm{J}$ & Combined & 3 & 3 & 4 & 3 \\
\hline
\end{tabular}

Table 3.1: Proportion of USU participants by JACS subject codes, by percentage.

Note that for some subject areas, this was a crude exercise. Some subjects (such as geography) will be coded by HESA either as '6' (for physical geography) or 'B' (for human geography), but many geography degrees combine instruction in both physical and human geography and many students will not be aware of the HESA and/or institutional code assigned to their particular degree programme. We have made an educated assumption when coding this subject (with the caveat that two of the research team have considerable experience as geography lecturers in higher education). We have coded any combined honours subject as 'J', where the degree programme title indicated by the student showed a division across two of the JACS subject areas. The JACS codes themselves are broad, grouping together more traditional degree subjects with more applied courses of study, so for example, biological sciences includes biology, zoology and biochemistry, along with applied programmes in sport and exercise. Social studies combines economics and anthropology alongside emergent academic disciplines such as criminology 


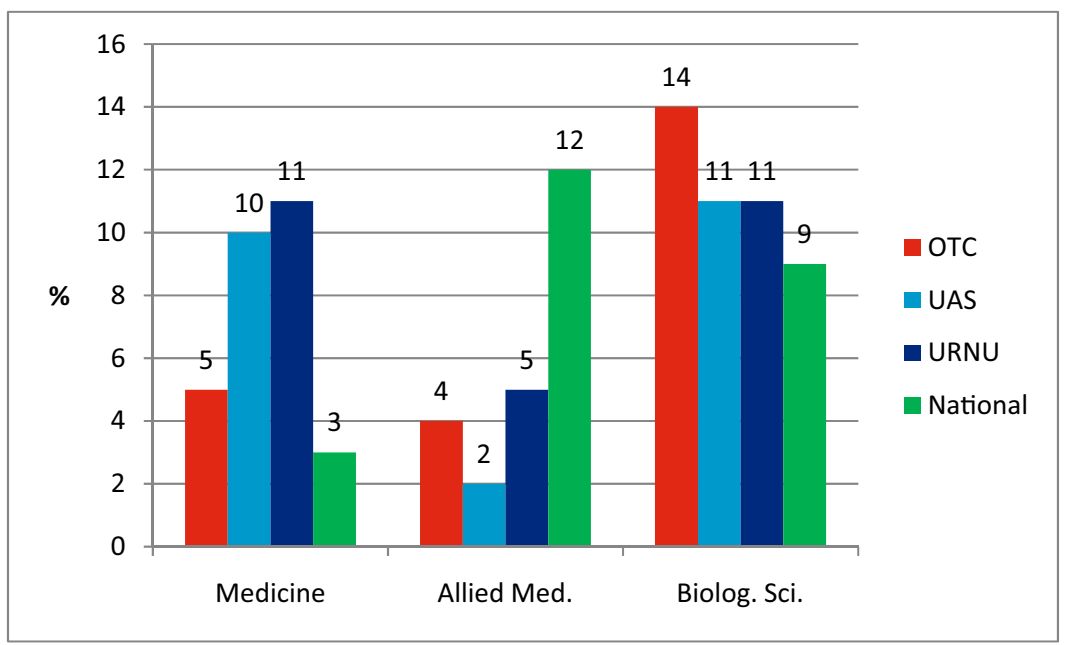

Figure 3.7: Percentage of USU participants registered on degree programmes in medicine, subjects allied to medicine and biological sciences.

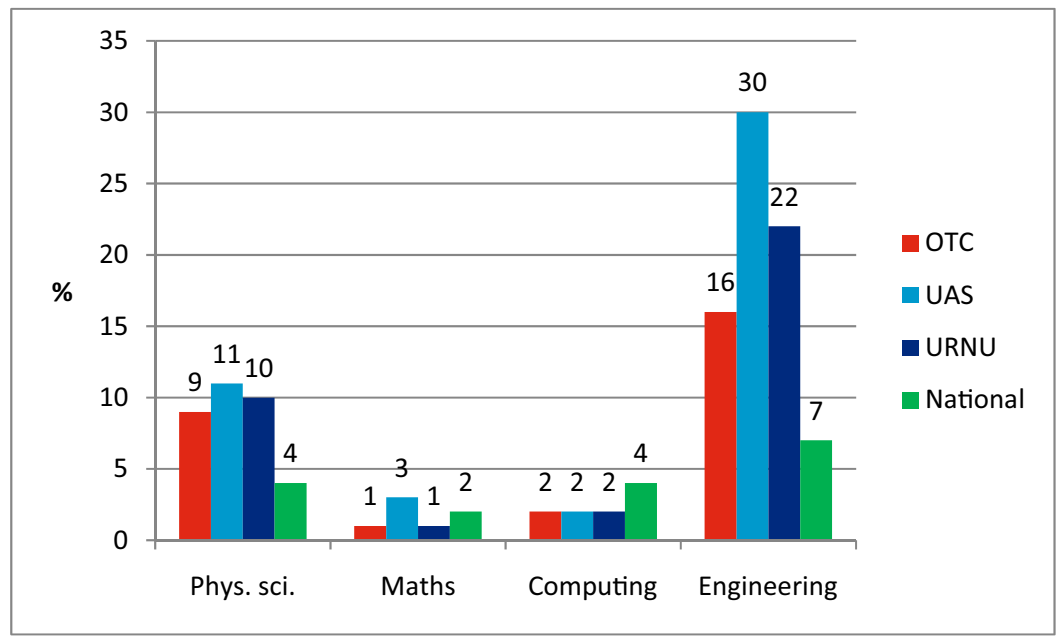

Figure 3.8: Percentage of USU participants registered on degree programmes in physical sciences, maths, computing and engineering.

and development studies. Note also that the HESA data used includes both full-time and part-time students (although the proportion taking part-time study is reducing nationally), and includes both undergraduate and postgraduate degrees. 


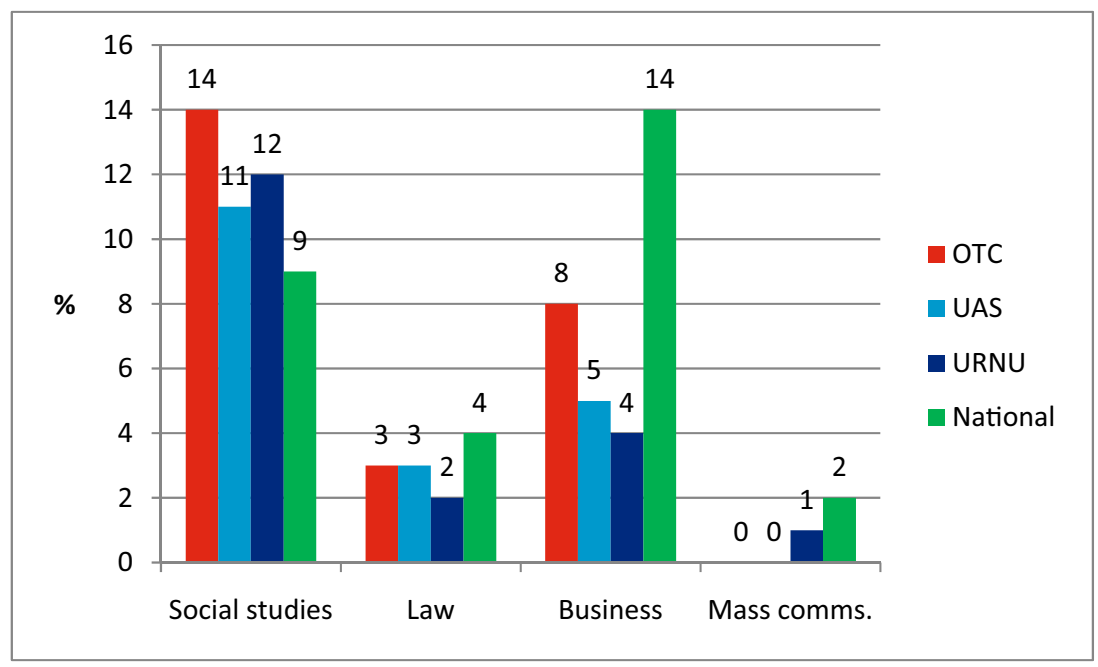

Figure 3.9: Percentage of USU participants registered on degree programmes in social studies, law, business and mass communications.

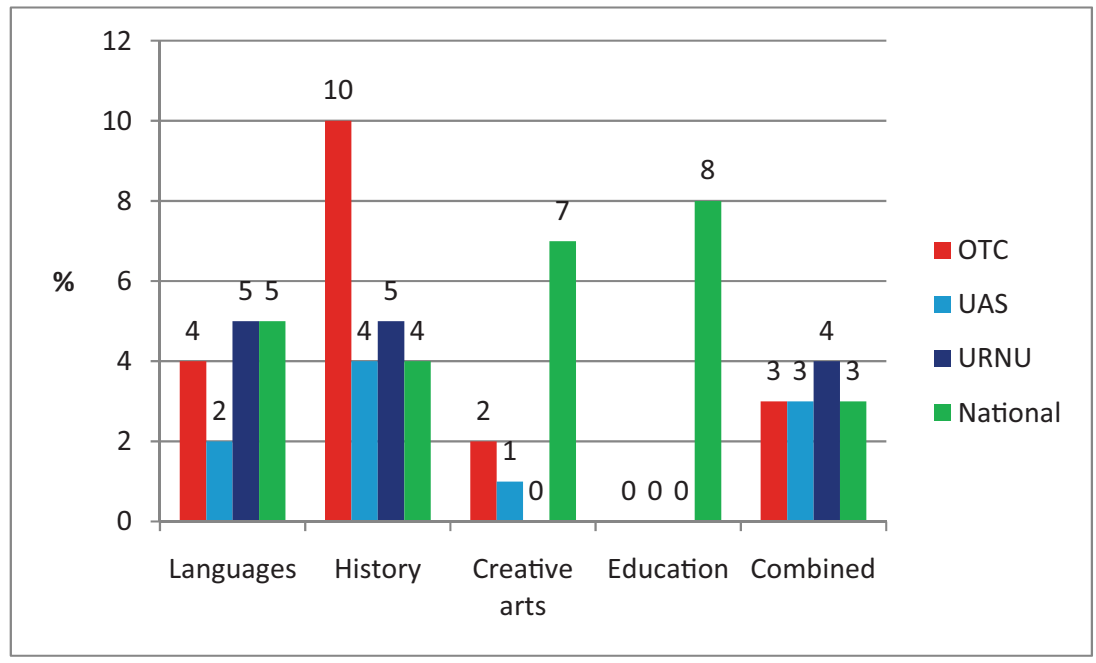

Figure 3.10: Percentage of USU participants registered on degree programmes in languages, historical studies, creative arts, education and combined studies.

In terms of comparisons between the service units, and against national rates of participation in degree programmes, some interesting points emerge. The proportions of USU participants taking degrees in medicine or biological sciences is above the national figure, and the reverse is the case for those 
taking subjects allied to medicine. The proportion of USU participants taking degrees in physical sciences or in engineering and technology is above the national figure, significantly so in the case of engineering, with $16 \%$ of OTC participants, $30 \%$ of UAS participants and $22 \%$ of URNU participants taking these subjects. The proportions taking social studies degrees is higher amongst USU participants, particularly those in the OTC, but lower for law, business and administrative studies, and in mass communications and documentation. The contrast between the proportion of OTC participants studying historical and philosophical studies compared with the other service units and the national picture is striking, as is the very small (and negligible) proportions of USU participants taking creative arts and design or education degrees.

Two points follow from this data, with the proviso that the indications given are potentially quite crude. The first is that there may be a correlation between the high proportions (particularly for UAS and URNU participants) taking engineering degrees, and the aspirations of those students for careers in aviation and marine engineering (within or beyond the RAF or Royal Navy). Students, in other words, may be making a strategic choice to participate in a USU as part of a package of activities undertaken at university aimed towards the pursuit of a particular career. The second point (see also 3.2.1 above) is that the degree subject patterns indicated above for USU participants may correlate quite directly with the dominance in the sample and in the USUs of students attending Russell Group universities, where certain subjects and approaches to subjects will dominate. This may also reflect the dominance of more traditional academic subjects studied by these students, where a significant proportion were educated in the independent sector where such subjects have continued to maintain purchase.

\subsubsection{Membership of other clubs and societies}

Across the USU survey participants, $60 \%$ indicated that they were members of other university or Student Union clubs or societies, and $40 \%$ indicated that they were not. This is of passing interest because it shows the extent to which USU participants engage across a range of other activities beyond their USU commitments. Sports activities dominated the list, with a much smaller proportion mentioning religious, political, music or degree subject-related societies, or voluntary or charitable activities. Sports clubs and activities arguably give a similar type of experience to students in terms of physical activity, and potentially too in terms of opportunities for the development of personal management and organisational skills. What is also notable is the relatively small number who included volunteering or community-based activities amongst USU members. We return to the question of the comparability or otherwise of the USU experience with other student activities in Chapter 7. 


\subsection{Joining a university armed service unit}

In this section, we consider pre-university awareness of the USUs, the mechanisms by which students find out about USUs and student motivations for joining.

\subsubsection{Awareness of university armed service units before arriving at university}

Students were asked about their awareness of the existence of the USUs prior to arrival at university, and if so, whether pre-existing knowledge was a factor in their choice of university (Table 3.2).

\begin{tabular}{|l|l|l|l|}
\hline Where you aware of USUs before arriving at university? & OTC & UAS & URNU \\
\hline No & 31 & 23 & 39 \\
\hline Yes, but it was NOT a factor in my choice of university & 52 & 44 & 49 \\
\hline Yes, and it was a factor in my choice of university & 17 & 32 & 11 \\
\hline
\end{tabular}

Table 3.2: Awareness of USUs prior to arriving at university, by percentage.

URNU members show the lowest levels of pre-entry awareness of the service units, and constitute the lowest proportion who considered the USUs to be a factor in their choice of university. There was greatest pre-university awareness amongst UAS members, with three quarters of them having existing knowledge, and just under one third seeing the existence of a squadron as influential in their choice of university. This may be explained by pro-activity on the part of potential members in seeking out access to flying experience because it is a scarce resource, coupled with awareness of the opportunities UAS participation might provide for entry into either a RAF career in aviation or in civilian aviation. Qualitative comments from the 207 respondents who identified the existence of a USU as a factor in their university choice illustrate this, with comments such as 'I wanted a place at a university linked to EMUAS', 'I confirmed my chosen university was affiliated to a USU' and 'I did not apply to any universities without an UOTC'. For some, it was a key part of their decision-making:

'I knew I wanted to join the UAS so I found all the universities associated with a UAS and found the course I wanted to do and went from there.'

'The fact that an URNU was located at Liverpool made me choose it over other (non-URNU) universities with similar entrance requirements.' 
For others, it was one of a number of factors:

'I looked out for mentions of OTC units in prospectuses - at the time I did not realise that several universities were affiliated to one base. Eventually this did not majorly change my choice of applications, as the course I decided to apply for is very specialist.'

'Received a leaflet for UOTC at a UCAS fair; whilst it was a small factor, it did lead me to look at some universities in a slightly more positive light.'

'When left in clearing with weaker academic reasons on choosing a university, the reputation of EMUOTC was a factor in choosing a university in the East Midlands.'

'I made sure that all of my chosen universities were affiliated with a UAS so I [could] join a UAS, but beyond that actual selection of university preference was solely on the degrees on offer and not the individual UASs.'

'Typed in university air squadron in Google and UBAS came up first, Coventry was one uni on their list and so it became one of my potential choices and ended up going there.'

'Although my university education is first and foremost, my choice of university reflected my interests in joining Glasgow \& Strathclyde URNU. My university career and URNU career enjoy nearly equal favourable status in prioritisation.'

This is a potentially significant finding, not least for universities working in a competitive undergraduate recruitment market.

Pre-university awareness of USUs is also differentiated by gender, and Table 3.3 shows pre-entry awareness of USUs amongst female survey respondents.

Over half of all female members of URNUs were not aware of the existence of the USUs before arriving at university, a lack of awareness repeated for the OTCs and UASs. In the OTCs $42 \%$ of women (compared with $27 \%$ of men) were not aware of the USUs. The proportion of women members of UASs using the existence of a unit as a factor in their choice of university was lower than for men, but still high. We discuss the wider issues raised by this question of differential awareness of USUs by gender in Chapter 7 .

\begin{tabular}{|l|r|r|r|}
\hline Where you aware of USUs before arriving at university? & OTC & UAS & URNU \\
\hline No & 42 & 38 & 55 \\
\hline Yes, but it was NOT a factor in my choice of university & 46 & 40 & 37 \\
\hline Yes, and it was a factor in my choice of university & 12 & 22 & 8 \\
\hline
\end{tabular}

Table 3.3: Awareness of USUs prior to arriving at university amongst women, by percentage. 


\subsubsection{Finding out about the university armed service units}

Survey respondents were asked about how they found out about the USU they eventually joined. The proportion from all three service units who received information directly from university careers services, Student Unions, a communication direct from a USU or via university or Student Union websites was minimal. Key sources of information are shown in Figure 3.11.

The Freshers' Fairs are evidently very significant as a mechanism by which students, on joining university, find out about the existence of the USUs. Freshers' Fairs appear to be particularly significant for the URNUs, which had the highest proportion of students unaware of the units prior to university. Freshers' Fairs are also slightly more significant for women than men: for the OTCs, $31 \%$ of female members identified Freshers' Fairs as initial sources of information, compared to $26 \%$ of male members. For the URNUs, it was the primary information source for $48 \%$ of women compared with $32 \%$ of men. For the UAS, it was the primary source of information for $30 \%$ of women and $18 \%$ of men.

The cadets (either single service or the combined cadet force) are also an important source of information and, we assume, encouragement to schoolaged students to consider USU participation at university. We asked explicitly about membership of uniformed youth organisations whilst at school. Results showed that $42 \%$ of OTC, $48 \%$ of UAS and $31 \%$ of URNU members had previously been in the cadets; in comparison, across the sample of USU members, a quarter had been in the Brownies, Cubs, Scouts or Guides. Overall, sources of information under direct control of the armed forces or service units, that is the cadets, armed forces careers service, leafleting and USU websites, were primary

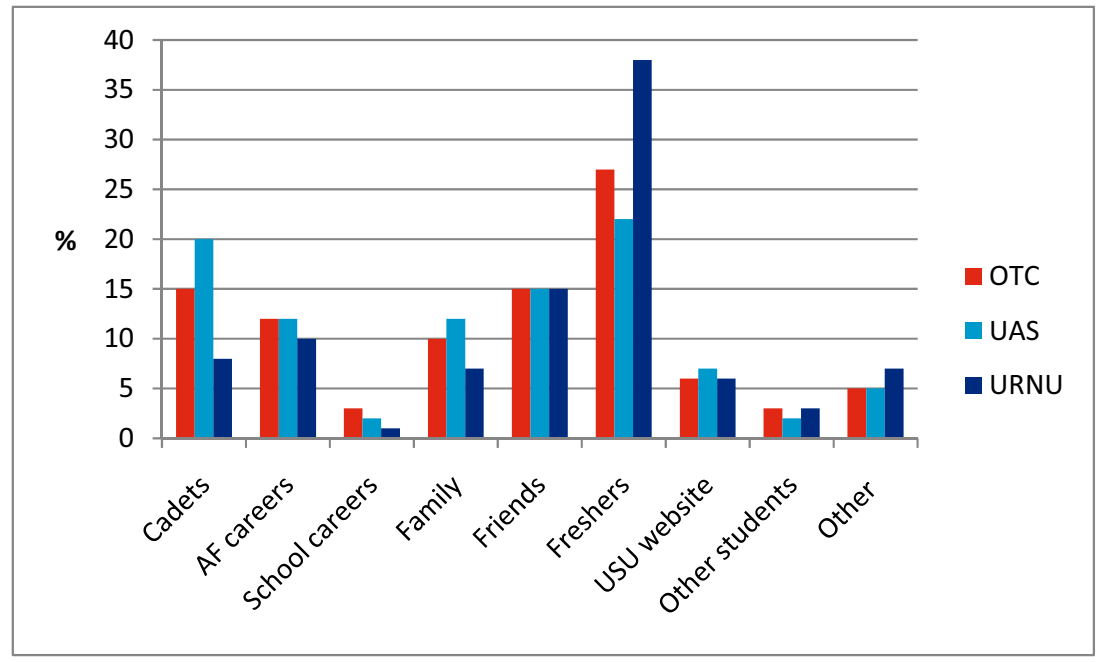

Figure 3.11: Significant sources of information about USUs, by percentage. 
sources of information for $35 \%$ of OTC, $40 \%$ of UAS and $24 \%$ of URNU members. Sources direct from the university and from the Student Union, were negligible as sources of information.

Social networks, meaning friends, family and other students, were a source of information for just over a quarter of participants (28\% of OTC, $29 \%$ of UAS and $25 \%$ of URNU members). We asked specifically about whether any relatives had been members of a USU, and $79 \%$ of OTC, $82 \%$ of UAS and $87 \%$ of URNU members said that they had no family connection. OTC members had the higher proportion of family connections, with $20 \%$ identifying a sibling, parent, grandparent or other close family member with USU membership.

We were also interested in whether the type of school attended was significant or influential in terms of finding out about USUs in the first place. For all USU members, the lowest proportion (20\% of USU members) using Freshers' Fairs as their primary information source had attended an independent sector fee-paying school as a boarder. In contrast, $31 \%$ USU members who had attended a further education or sixth form college as a non-boarder identified Freshers' Fairs as their primary source of information, as did $25 \%$ of USU members who had attended state school as day pupils. We would suggest that Freshers' Fairs are more significant as a source of information for those attending state sector education.

Where respondents identified 'other' as an initial source of information, we asked for elaboration. Seemingly random browsing through websites was a significant here:

'While at school a few of us were looking at OTCs, researched it myself really. Leeds happened to have one, turns out a very good example of an OTC from my interaction with other South Yorkshire based units [...] and joined when I arrived at University?

There were also chance encounters with individuals from the armed forces, or visits to schools by representatives from the armed forces, and even quite random encounters which turned out to be influential:

'Dancing at the Edinburgh Tattoo and meeting members of the OTC who were performing as pirates and fishermen and getting paid for it whereas I was not.'

\subsubsection{Motivations for joining a university armed service unit}

We were interested in student motivations for joining a USU, and asked respondents to identify factors motivating enlistment (students could select all that applied to them). Table 3.4 shows the patterns of choice across the three services and for the USUs as a whole, and Figure 3.12 presents this data graphically for ease of comparison. 


\begin{tabular}{|l|r|r|r|r|}
\hline \multicolumn{1}{|c|}{ Motivation } & OTC & UAS & URNU & \multicolumn{1}{c|}{ All USUs } \\
\hline Adventurous training opportunities & 71 & 85 & 70 & 76 \\
\hline Armed Forces or MoD bursary & 12 & 10 & 7 & 10 \\
\hline For the challenge & 72 & 70 & 64 & 70 \\
\hline CV enhancement & 59 & 57 & 58 & 58 \\
\hline Flying opportunities & 1 & 84 & 13 & 33 \\
\hline Interest in the military & 80 & 86 & 71 & 81 \\
\hline Pay & 59 & 28 & 38 & 44 \\
\hline Sailing/nautical skills & 6 & 9 & 59 & 15 \\
\hline Shooting & 24 & 27 & 7 & 22 \\
\hline Sport & 34 & 60 & 38 & 44 \\
\hline Transferable skills & 57 & 71 & 63 & 63 \\
\hline University course credits & $<1$ & 1 & $<1$ & $<1$ \\
\hline Wanting to develop military skills & 55 & 52 & 42 & 51 \\
\hline Other & & & & 10 \\
\hline
\end{tabular}

Table 3.4: Motivations for joining by service unit, by percentage.

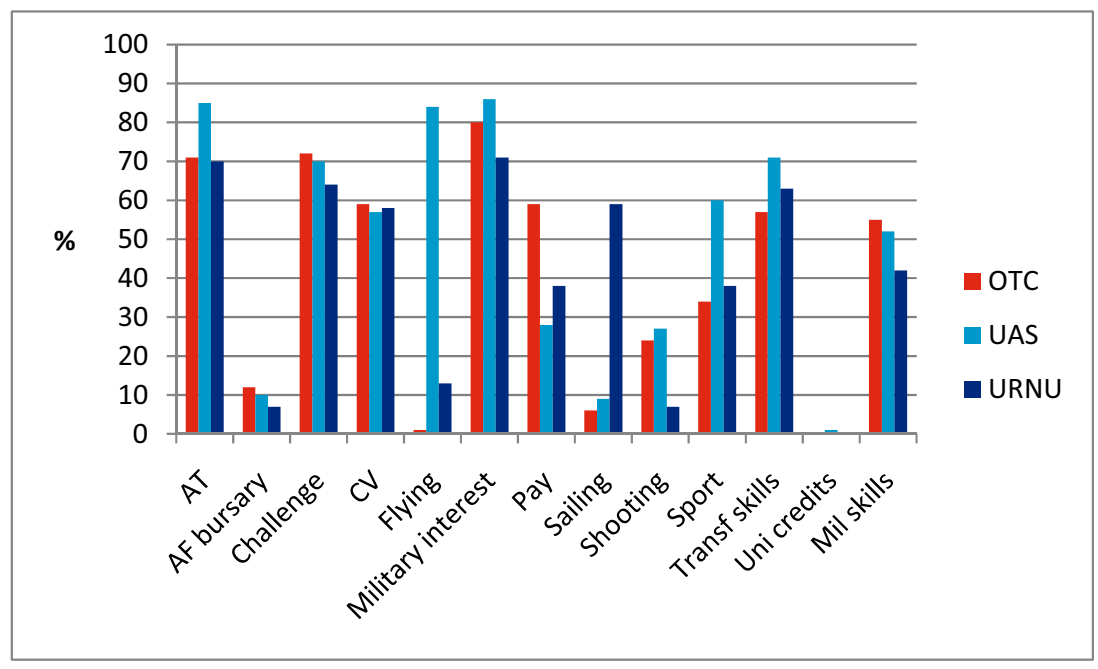

Figure 3.12: Motivations for joining by service unit, by percentage.

There are some very obvious differences in motivations between the units, with $84 \%$ of UAS members identifying 'flying opportunities', $59 \%$ of URNU members identifying 'sailing/nautical skills' and $24 \%$ of OTC and $27 \%$ of UAS 
members identifying 'shooting skills'. Overall, 'interest in the military' is the most commonly identified reason, with $81 \%$ of USU members selecting this, although note the difference between UAS and URNU members, with $86 \%$ and $71 \%$ respectively. Pay is a more commonly cited motivator for OTC (59\%) than URNU (38\%) or UAS (28\%) members; for UAS members, the access to a flying opportunity (a scarce resource) is clearly more significant. There are differences too between the three services in terms of transferable skills, with a higher proportion of UAS members identifying transferable skills (71\%) as a motivator than URNU (63\%) or OTC (57\%) members. Sport is more commonly identified as a motivator for UAS (60\%) rather than OTC and URNU members.

If we compare motivations for joining not just across the three services, but between men and women in each service, we see a slightly different picture. Table 3.5 provides the data, and Figures 3.13, 3.14 and 3.15 show this information graphically for ease of comparison.

A higher proportion of men identify 'military interest' and 'military skills' as motivations for joining the OTC compared with women. A slightly higher proportion of women identify 'adventurous training' and 'for the challenge', 'sport'

\begin{tabular}{|l|r|r|r|r|r|r|}
\hline \multicolumn{1}{|c|}{ Motivation } & \multicolumn{1}{c|}{$\begin{array}{c}\text { OTC } \\
\text { men }\end{array}$} & \multicolumn{1}{c|}{$\begin{array}{c}\text { OTC } \\
\text { women }\end{array}$} & $\begin{array}{c}\text { UAS } \\
\text { men }\end{array}$ & \multicolumn{1}{c|}{$\begin{array}{c}\text { UAS } \\
\text { women }\end{array}$} & $\begin{array}{c}\text { URNU } \\
\text { men }\end{array}$ & $\begin{array}{c}\text { URNU } \\
\text { women }\end{array}$ \\
\hline $\begin{array}{l}\text { Adventurous training } \\
\text { opportunities }\end{array}$ & 70 & 74 & 86 & 85 & 72 & 67 \\
\hline $\begin{array}{l}\text { Armed Forces/MoD } \\
\text { bursary }\end{array}$ & 15 & 6 & 11 & 9 & 7 & 4 \\
\hline For the challenge & 70 & 72 & 68 & 73 & 58 & 74 \\
\hline CV enhancement & 59 & 57 & 59 & 55 & 59 & 58 \\
\hline Flying opportunities & 1 & 2 & 89 & 76 & 13 & 12 \\
\hline Interest in the military & 85 & 69 & 91 & 76 & 83 & 54 \\
\hline Pay & 63 & 50 & 32 & 22 & 40 & 35 \\
\hline Sailing/nautical skills & 7 & 7 & 9 & 10 & 60 & 60 \\
\hline Shooting & 27 & 17 & 31 & 21 & 10 & 4 \\
\hline Sport & 30 & 44 & 59 & 62 & 38 & 39 \\
\hline Transferable skills & 57 & 59 & 72 & 69 & 64 & 64 \\
\hline $\begin{array}{l}\text { Wanting to develop } \\
\text { military skills }\end{array}$ & 63 & 35 & 60 & 37 & 50 & 31 \\
\hline
\end{tabular}

Table 3.5: Motivations for joining a USU by service unit and gender, by percentage. 


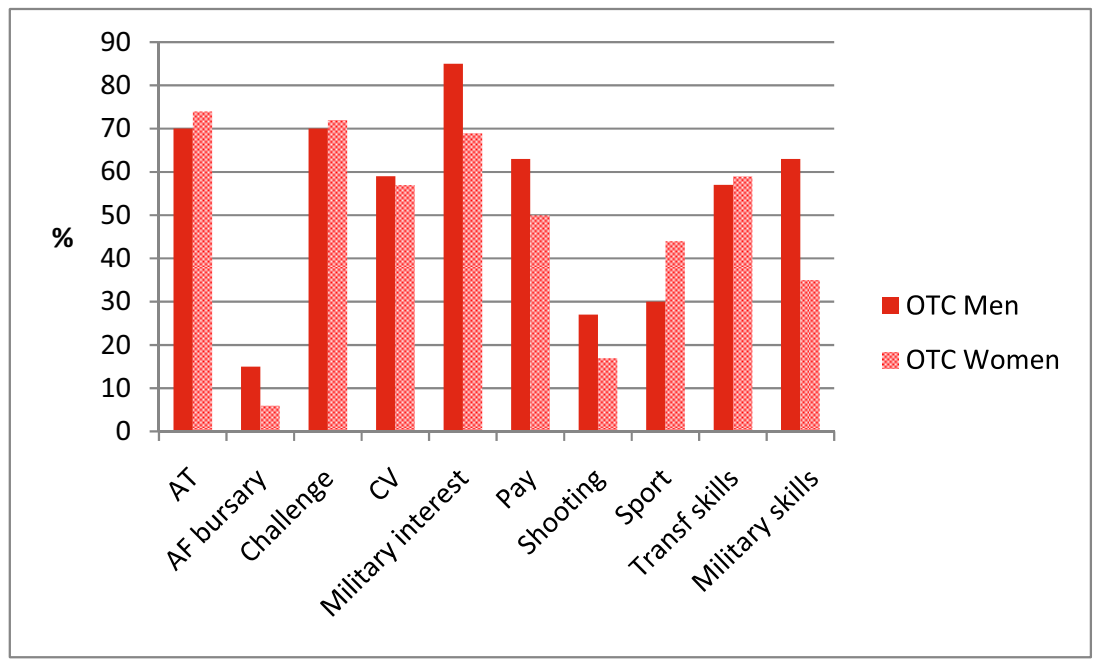

Figure 3.13: Motivations for joining OTC, by gender.

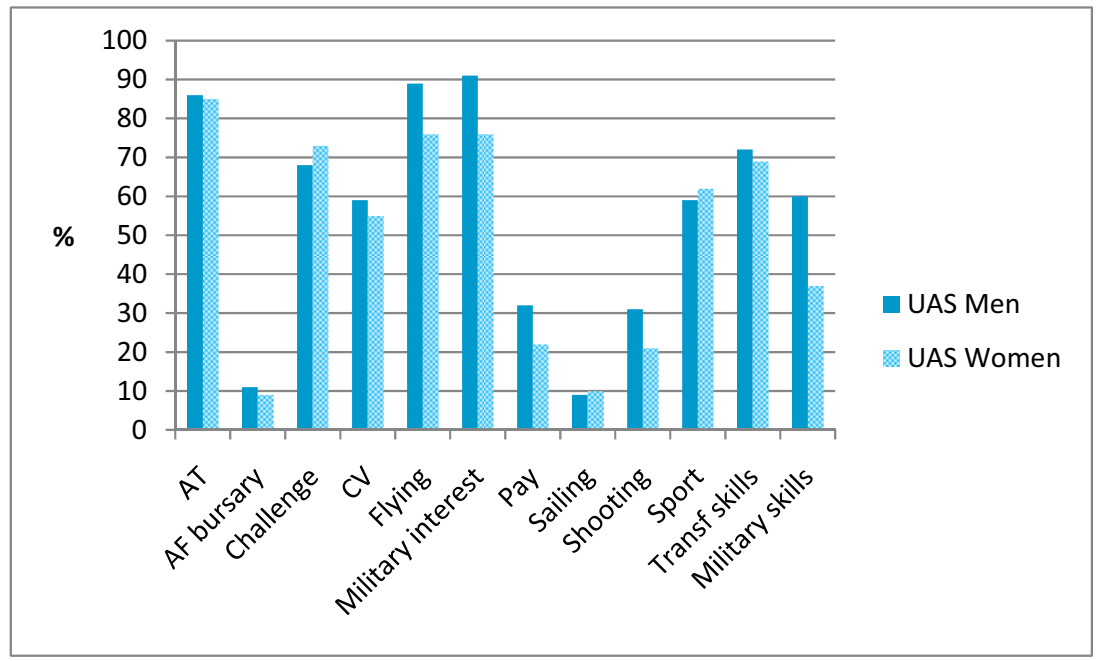

Figure 3.14: Motivations for joining UAS, by gender.

and 'transferable skills' than men as motivators for joining the OTC. In both the UAS and URNU, a higher proportion of women identify 'for the challenge' as a motivator for joining than men, and this is particularly marked in the URNU.

We also disaggregated motivations for joining by length of USU participation, but this exercise showed no clear patterns across the various cohorts of 


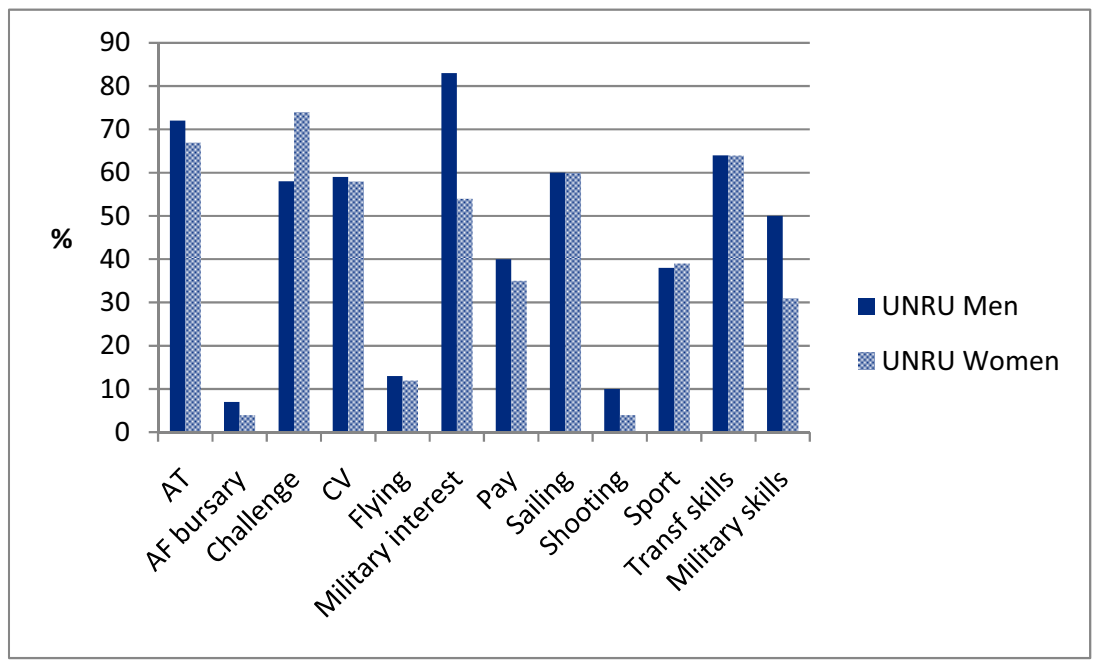

Figure 3.15: Motivations for joining URNU, by gender.

participants. For example, the proportions identifying adventurous training as a motivation remained fairly constant across different lengths of participation within each service unit.

\subsection{University armed service units and skills development}

One of the motivators for this research was to investigate the value of the USUs in terms of the skills development for students. As we indicated in the introductory chapter and above, this is an issue of interest in both the higher education sector and a motivation for students joining a unit.

Within universities, various schema exist to identify the nature of the graduate or transferable skills a university education might be expected to inculcate in students, beyond the subject-specific knowledge which their degree programme will have provided. In this research, we drew on the graduate skills framework developed at Newcastle University from 2010 onwards to devise a set of survey questions to establish both whether or not respondents considered their USU and their degree programmes to have helped them develop specific skills, and also to assess the extent to which students considered these skills to have been developed. Appendices 6 and 7 provide the data used to develop the graphics shown in the following figures, which compare student evaluations for each skill in turn. Note that the appendices list the skills in alphabetical order as they appeared in the original survey. In sections 3.4.1-3, we group skills together according to the categories used by 
the Newcastle graduate skills framework, and section 3.4.4 groups together an additional set of USU-specific skills included in the questions as part of the survey (and which are not included in the Newcastle University framework). For each skill, a Likert scale was used for respondents to evaluate the development of that particular skill, with respondents choosing between the categories 'not at all', 'some but not as much as I would like', 'about as much as I had anticipated', 'more than I had anticipated' and 'way beyond my expectations'. Respondents were also given the option 'not applicable', which we have excluded from the graphs.

In all the graphs that follow, we combine the data from the tables given in Appendices 6 and 7 to show, side by side according to each of the five points on the Likert scale, the proportion of students in each of the three service units making that assessment first (in plain colour shading) of their USU experience, and then (in stippled colour shading) of their university degree. The graphs which follow thus make it possible to see how students in each of the three units rate their skills development from both their USU and their degree programme experience.

\subsubsection{Cognitive and intellectual skills}

This set of skills comprises critical thinking (Figure 3.16), numeracy (Figure 3.17), literacy (Figure 3.18), information literacy (Figure 3.19) and synthesising information (Figure 3.20).

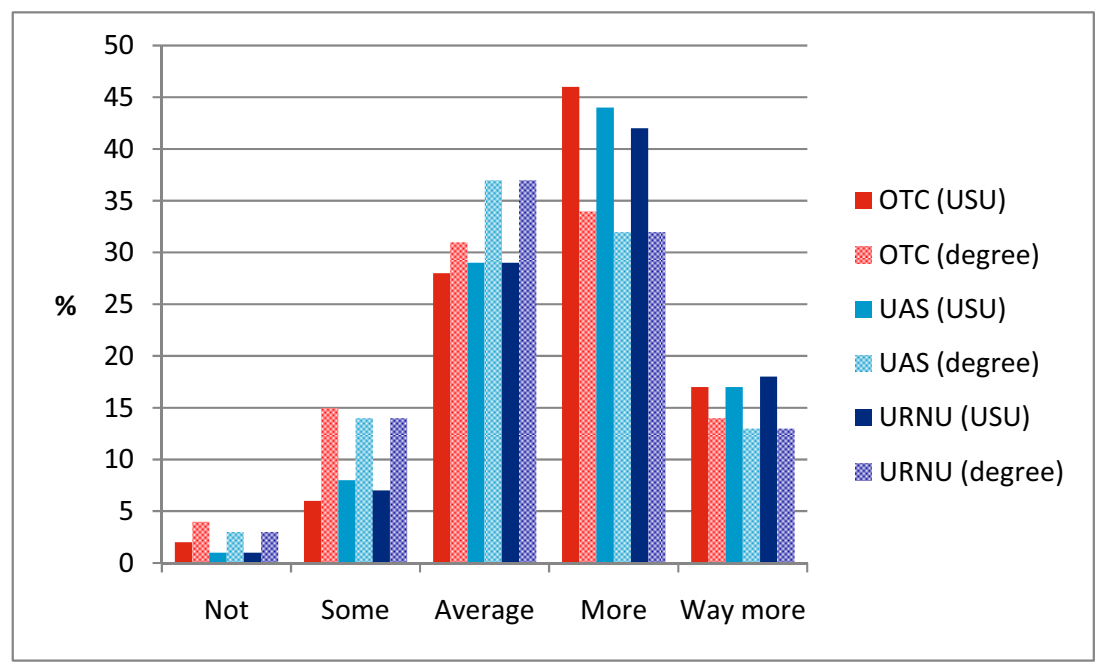

Figure 3.16: Critical thinking: student evaluations of USU and university degree. 


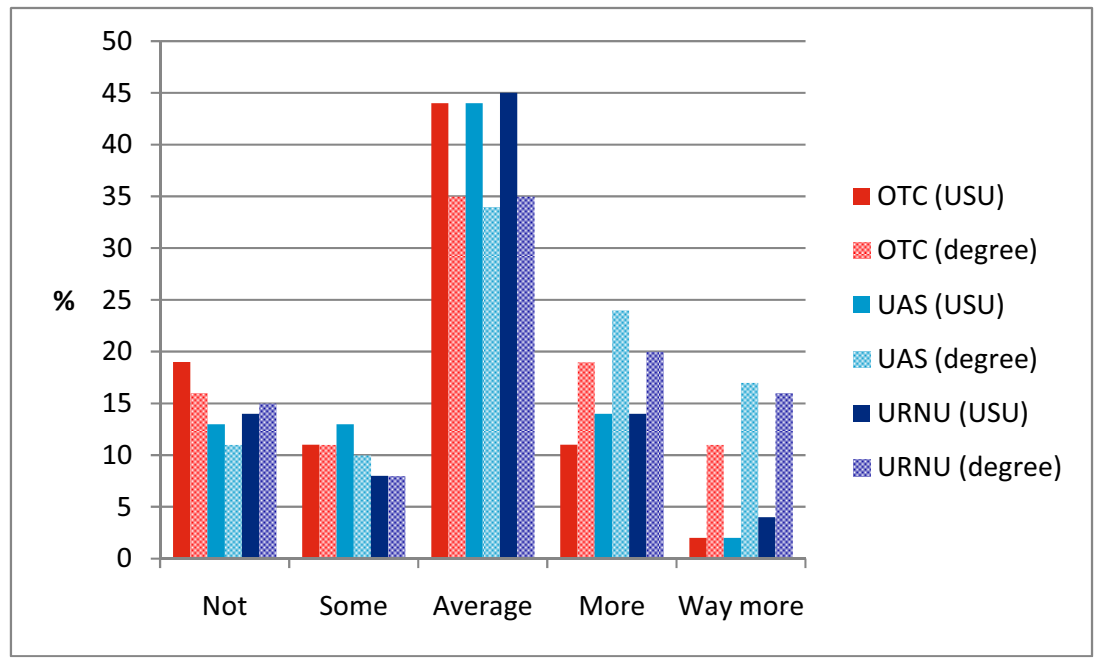

Figure 3.17: Numeracy: student evaluations of USU and university degree.

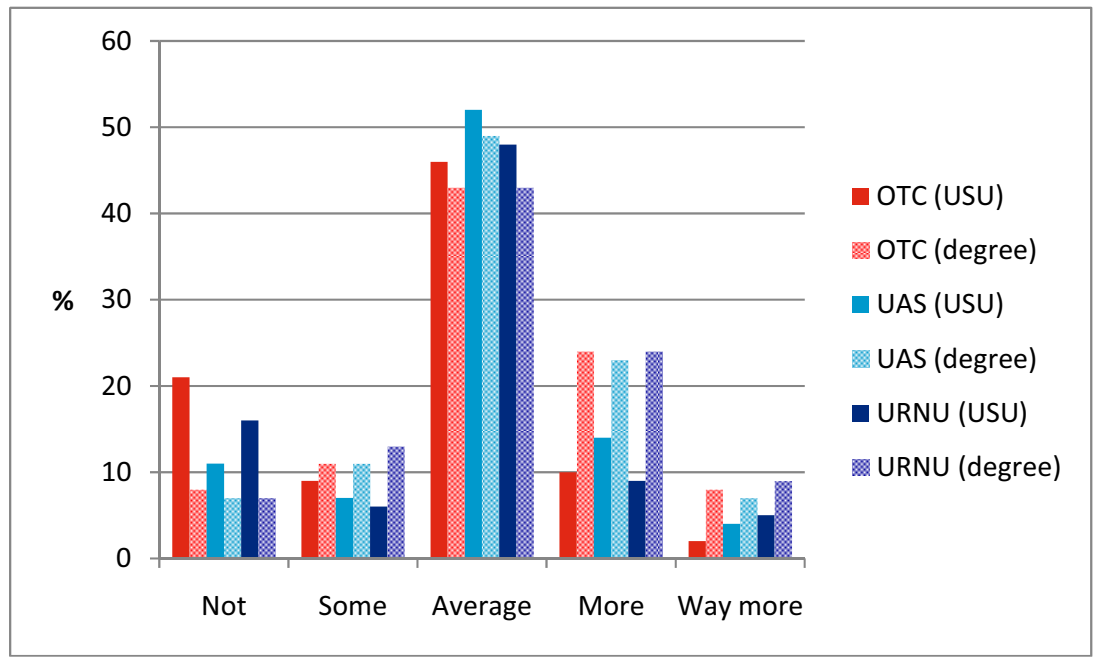

Figure 3.18: Literacy: student evaluations of USU and university degree.

The figures above show student evaluations (disaggregated by service unit) for their USU experience alongside their university experience. Student evaluations of cognitive and intellectual skills developed through degree programmes shows a broadly normal distribution. As might be expected, the skills in 


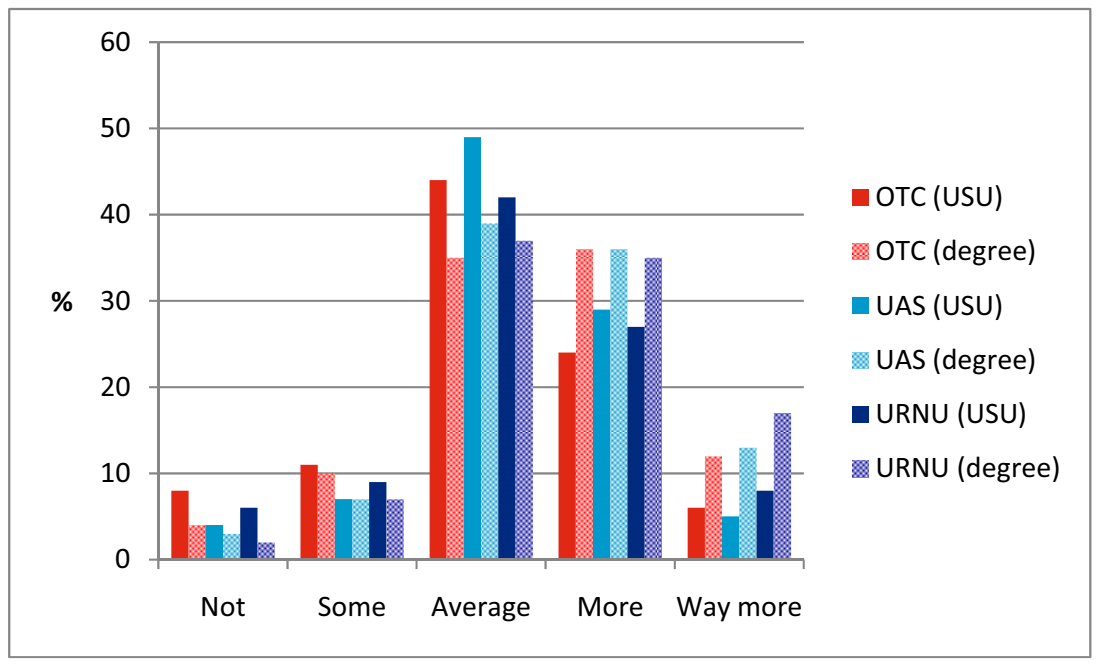

Figure 3.19. Information literacy: student evaluations of USU and university degree.

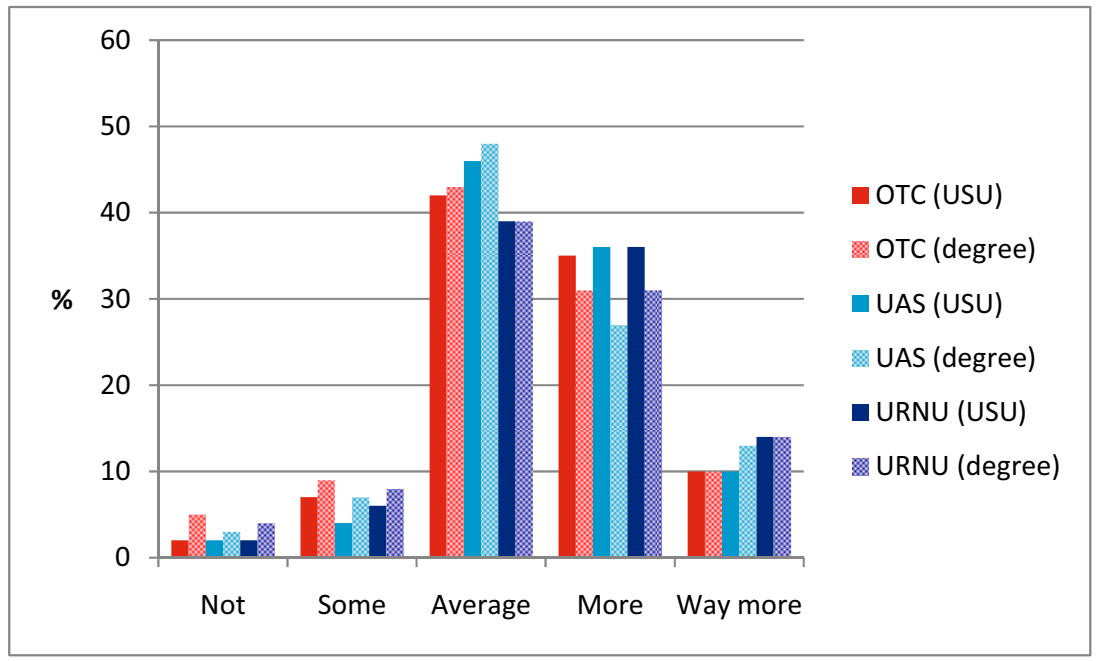

Figure 3.20: Synthesising information: student evaluations of USU and university degree.

numeracy, literacy, information literacy and synthesising information-skills which a tertiary-level education at university set out explicitly to develop-are evaluated as being developed 'more' and 'way more' at a higher rate by students through their university degrees than through their USU participation. 
What is interesting here are the comparisons between evaluations for critical thinking between the USU experience and the university degree experience (Figure 3.16), which at the levels of 'more' and 'way more' for the USU experience, exceed those for the university degree. This suggests that USU participants both perceive that their USU experience helps them develop their critical thinking skills, and also that their level of expectation about the development of this skill in their USU activities exceeds that for their university education. Although, because of the quantitative questionnaire-based methodology we are unable to pinpoint precisely how and why students reach this conclusion, this is certainly an informative finding for those charged with skills development in both USU and university contexts.

\subsubsection{Self-management skills}

This set of skills comprises organisation and planning (Figure 3.21), project planning (Figure 3.22), decision-making (Figure 3.23), initiative (Figure 3.24), independence (Figure 3.25), adaptability (Figure 3.26), problem-solving (Figure 3.27), time management (Figure 3.28) and budgeting (Figure 3.29). Student evaluations of their USU experience and their university degree in developing these skills are shown in the following figures.

For self-management skills, student evaluations of the development of these skills through their university programme show a normal distribution, with the exception of budgeting. In comparison, student evaluations of the development

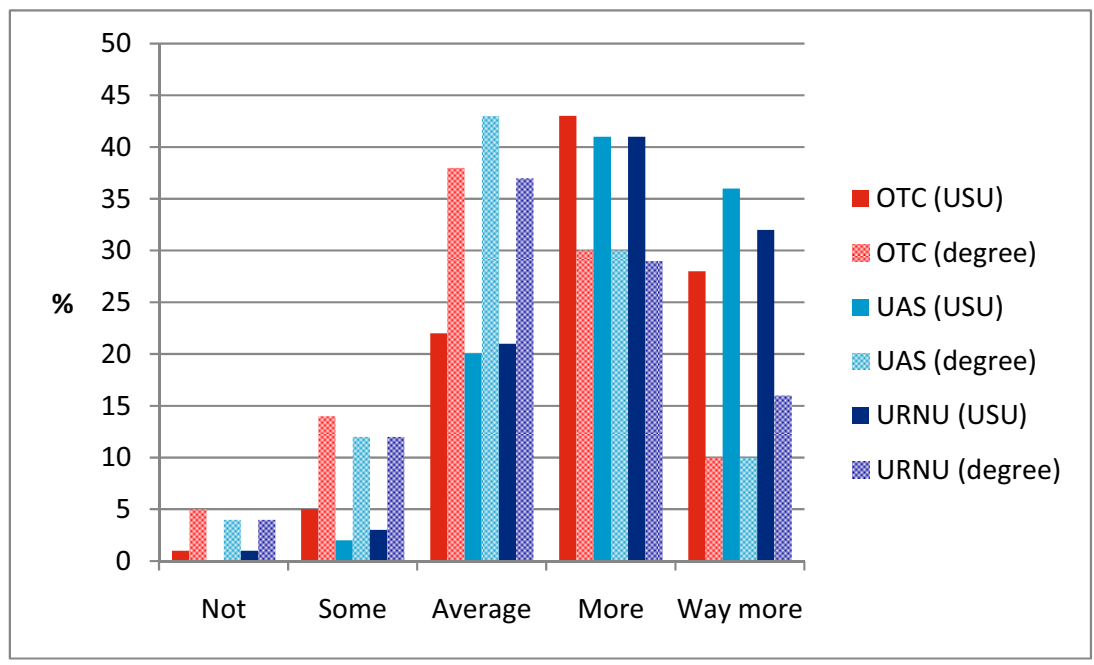

Figure 3.21: Organisation and planning: student evaluations of USU and university degree. 


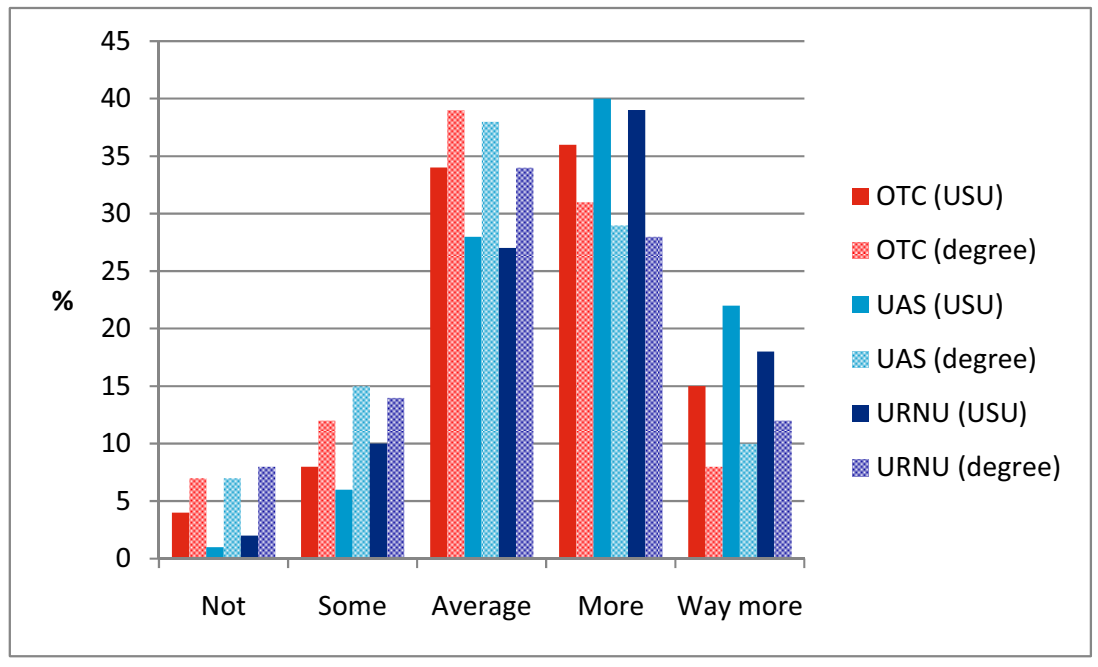

Figure 3.22: Project planning: student evaluations of USU and university degree.

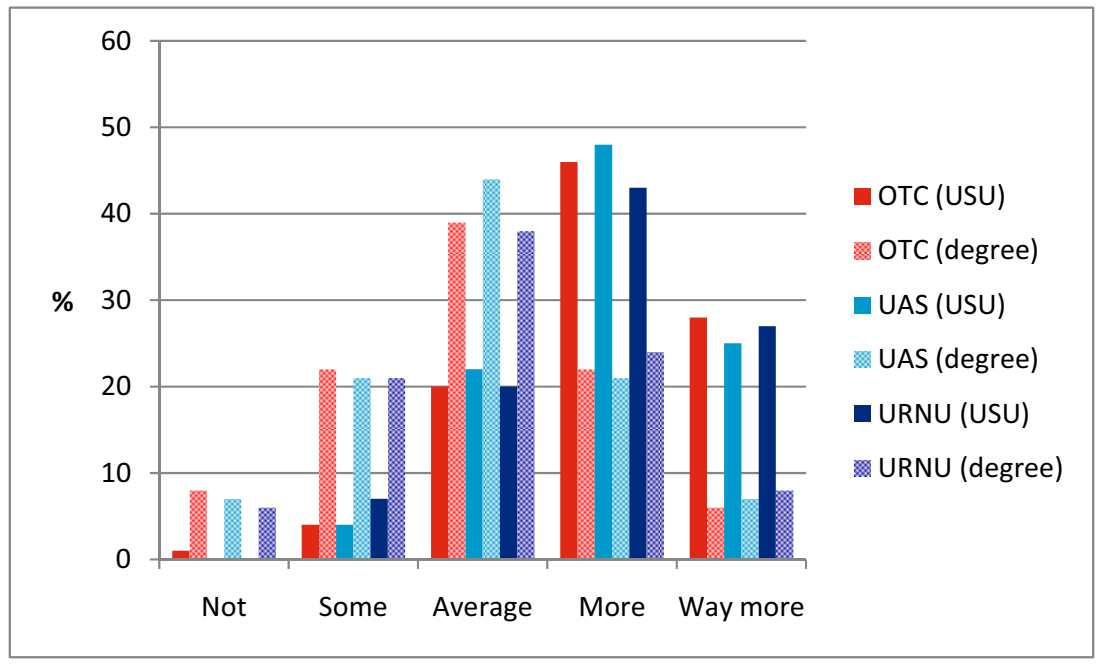

Figure 3.23: Decision-making: student evaluations of USU and university degree. 


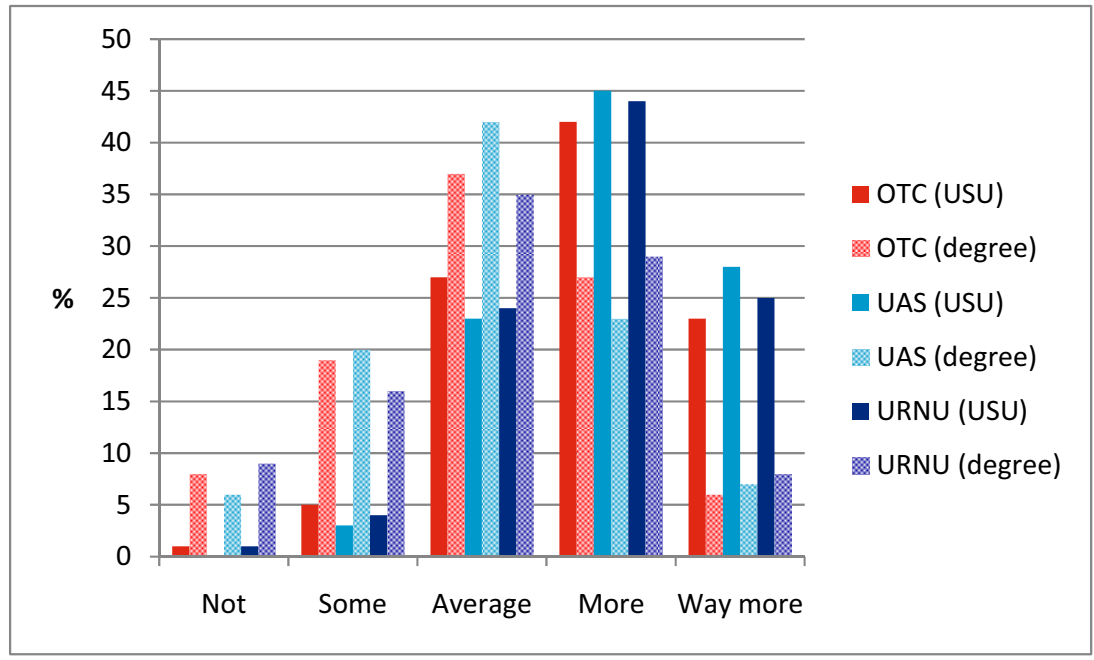

Figure 3.24: Initiative: student evaluations of USU and university degree.

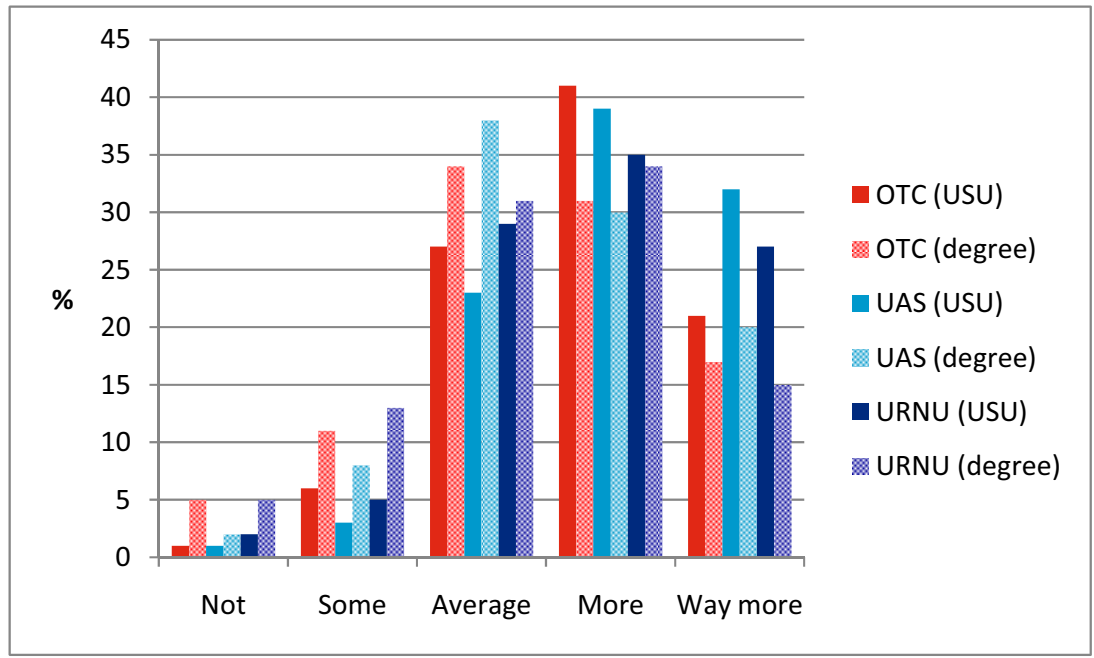

Figure 3.25: Independence: student evaluations of USU and university degree. 


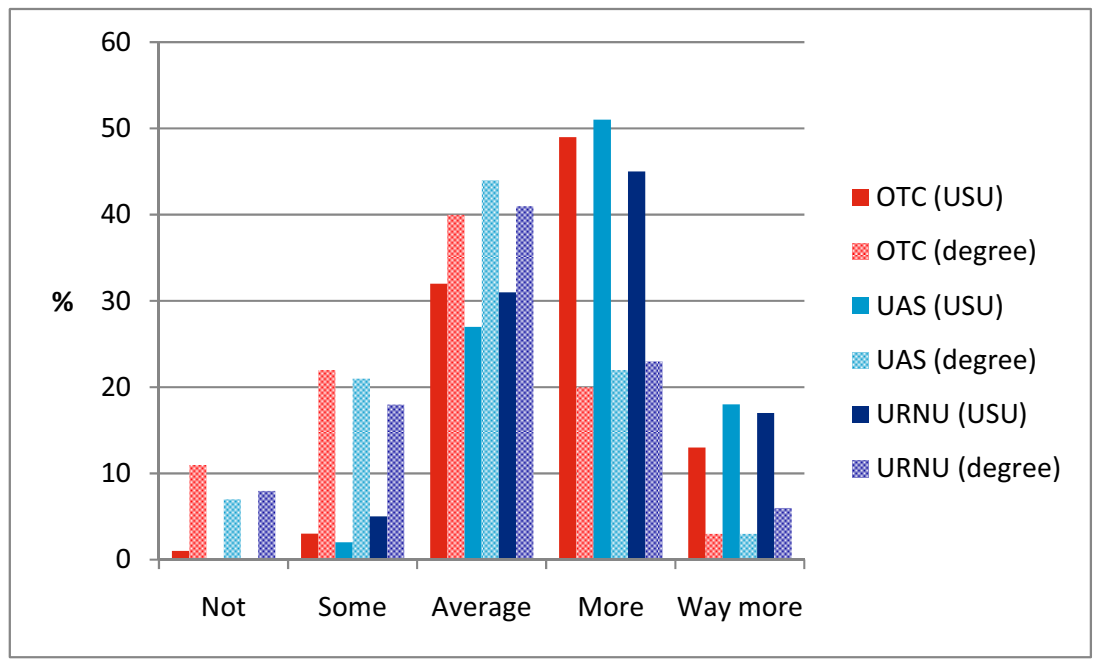

Figure 3.26: Adaptability: student evaluations of USU and university degree.

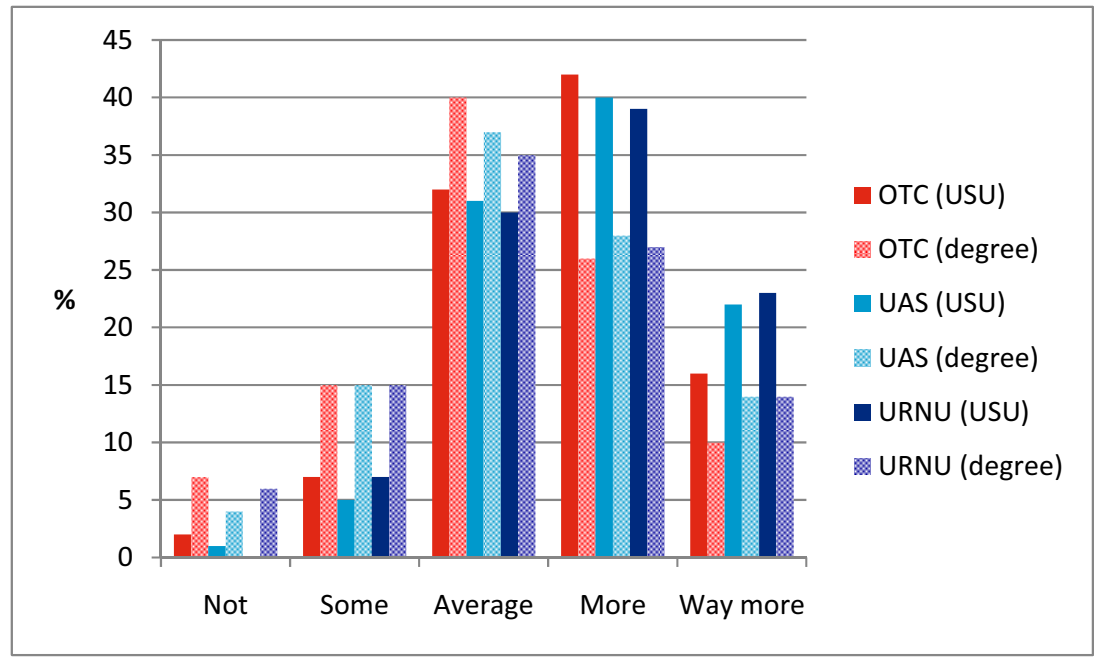

Figure 3.27: Problem-solving: student evaluations of USU and university degree. 


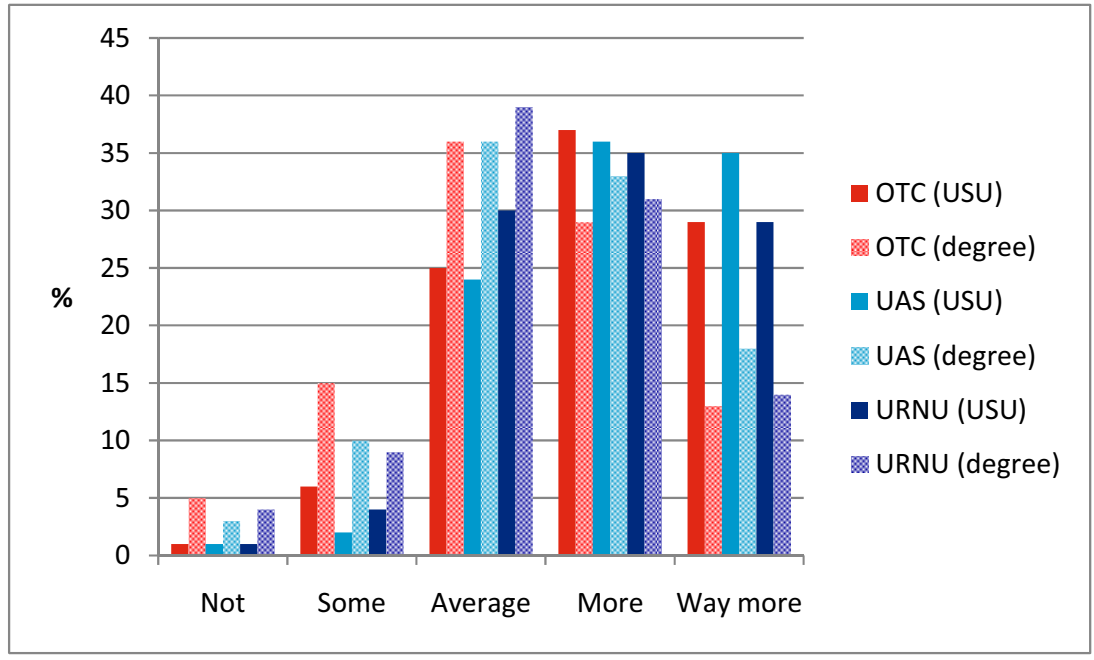

Figure 3.28: Time management: student evaluations of USU and university degree.

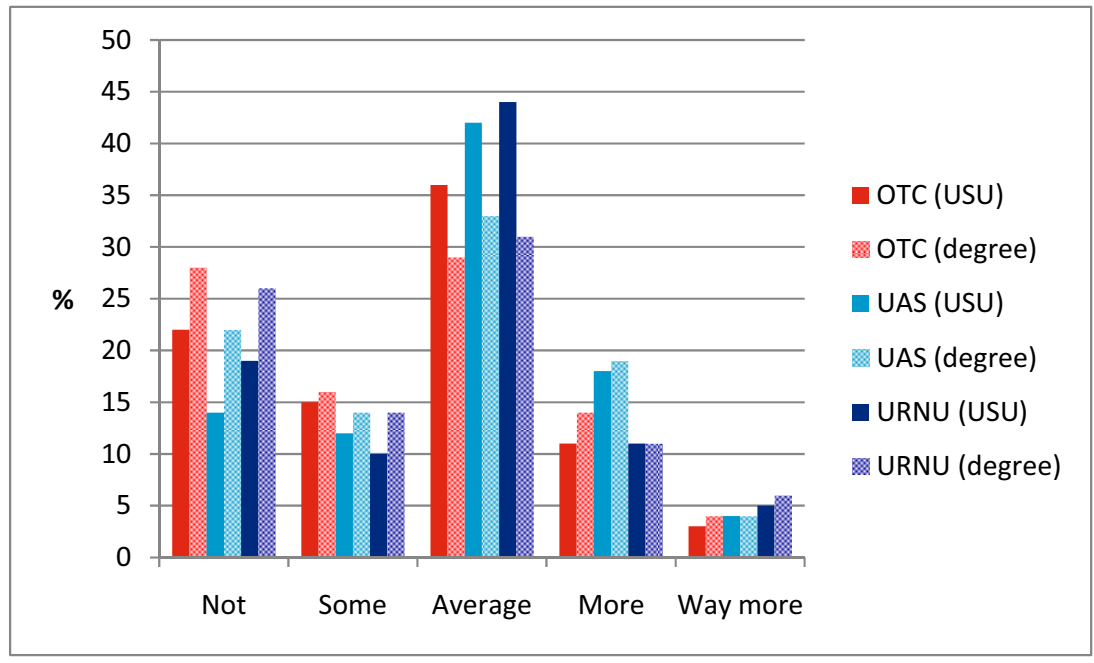

Figure 3.29: Budgeting: student evaluations of USU and university degree. 
of self-management skills, with the exception of budgeting, show a markedly higher proportion considering that they had developed these skills 'more' and 'way more' through USU participation. From this, we suggest not only that students participating in USUs indicate that they are developing a range of selfmanagement skills through this activity, but also that a significant proportion consider the level to which they have been able to do so to have exceeded their expectations quite considerably. Furthermore, this suggests that skills training at both university and USU levels are beyond participants' expectations, having not expected this as a focus of their activities, rather than any indication that this was necessary a good or bad thing. Once these activities become normalised as part of student expectations, we would expect a normal bell curve to reassert itself.

\subsubsection{Interaction skills}

This set of skills comprises communication skills (Figure 3.30), verbal interaction (Figure 3.31), presentation skills (Figure 3.32), leadership (Figure 3.33) and teamwork (Figure 3.34). Student evaluations of their USU experience and their university degree in developing these skills are shown in the following figures.

For the interaction skills of communication, verbal interaction, presentation and teamwork, student evaluations of the extent to which these have been developed through their university degree reflect a normal distribution. Of

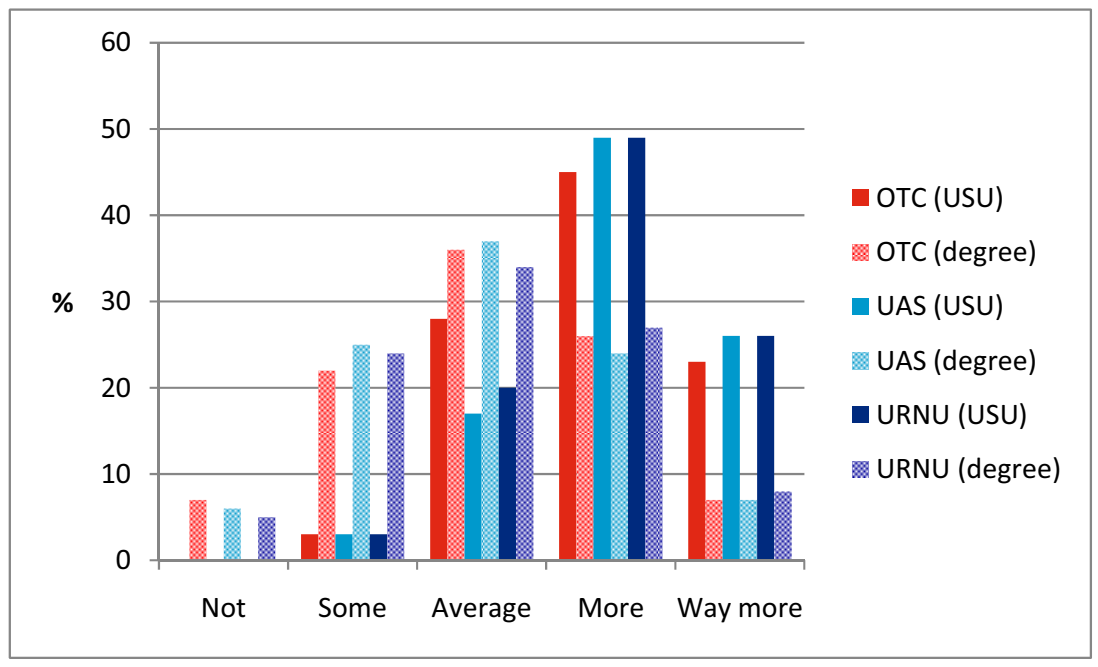

Figure 3.30: Communication skills: student evaluations of USU and university degree. 


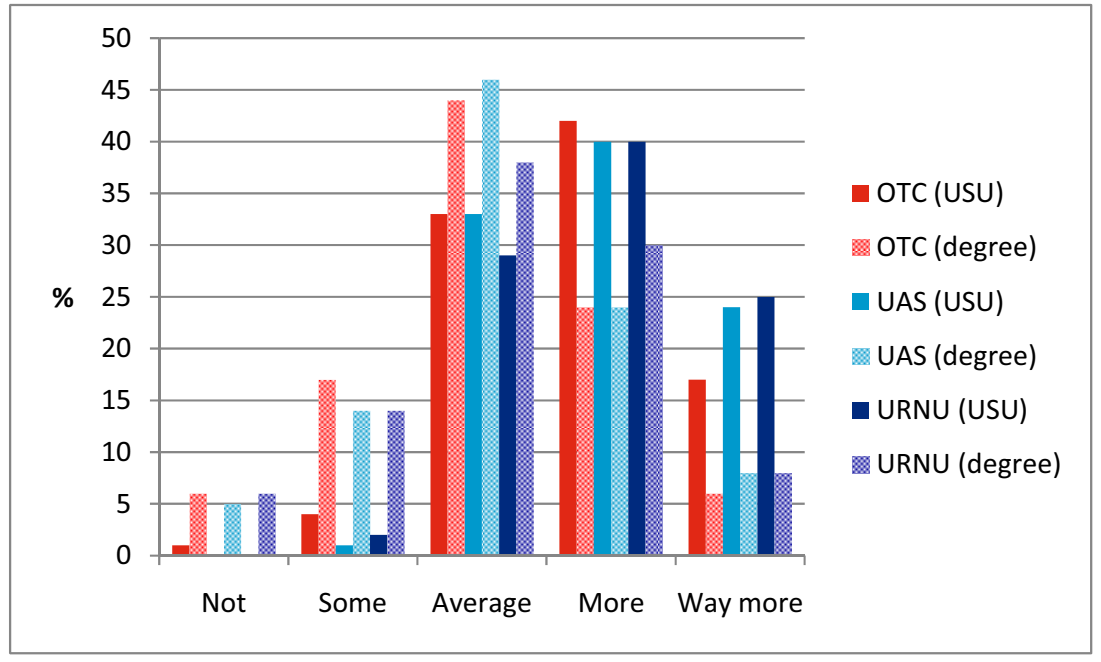

Figure 3.31: Verbal interaction: student evaluations of USU and university degree.

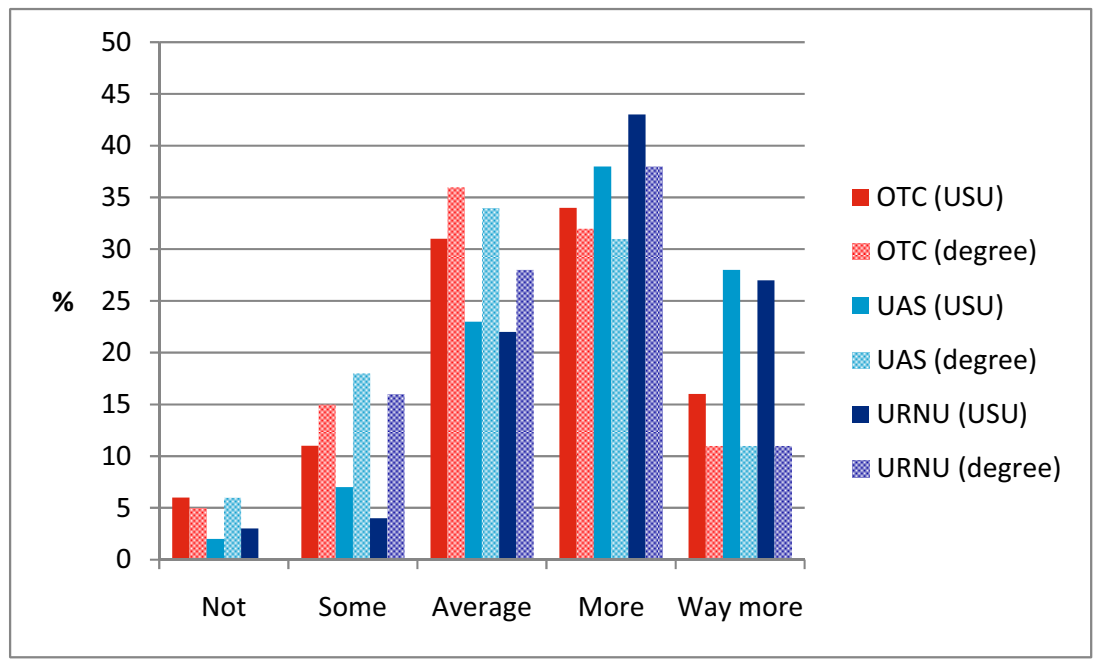

Figure 3.32: Presentation skills: student evaluations of USU and university degree. 


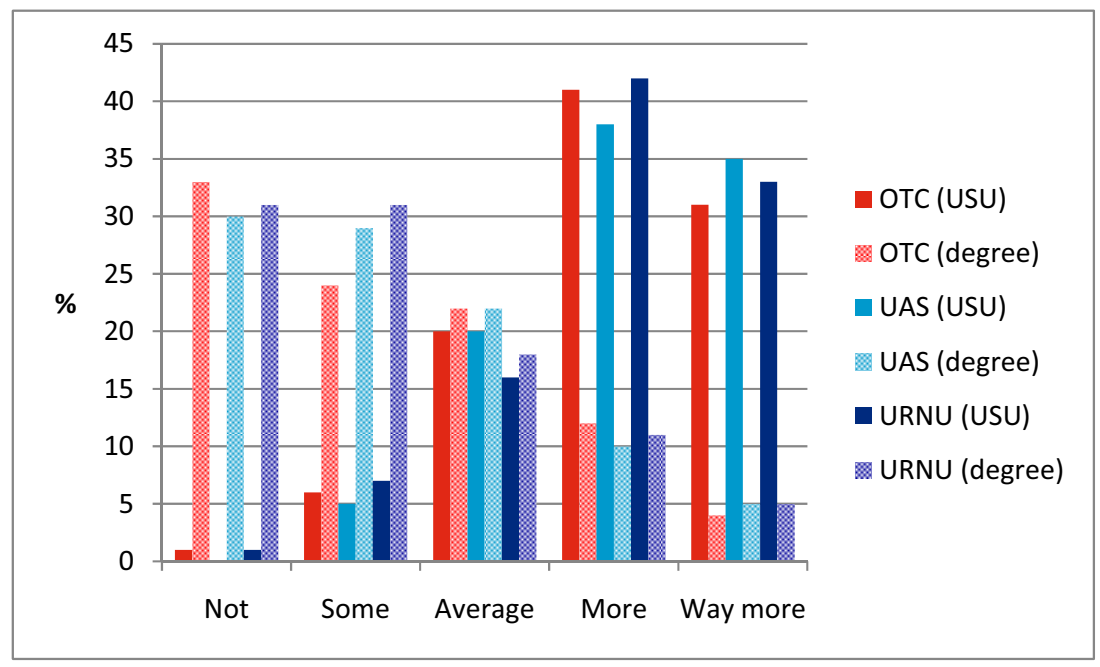

Figure 3.33: Leadership: student evaluations of USU and university degree.

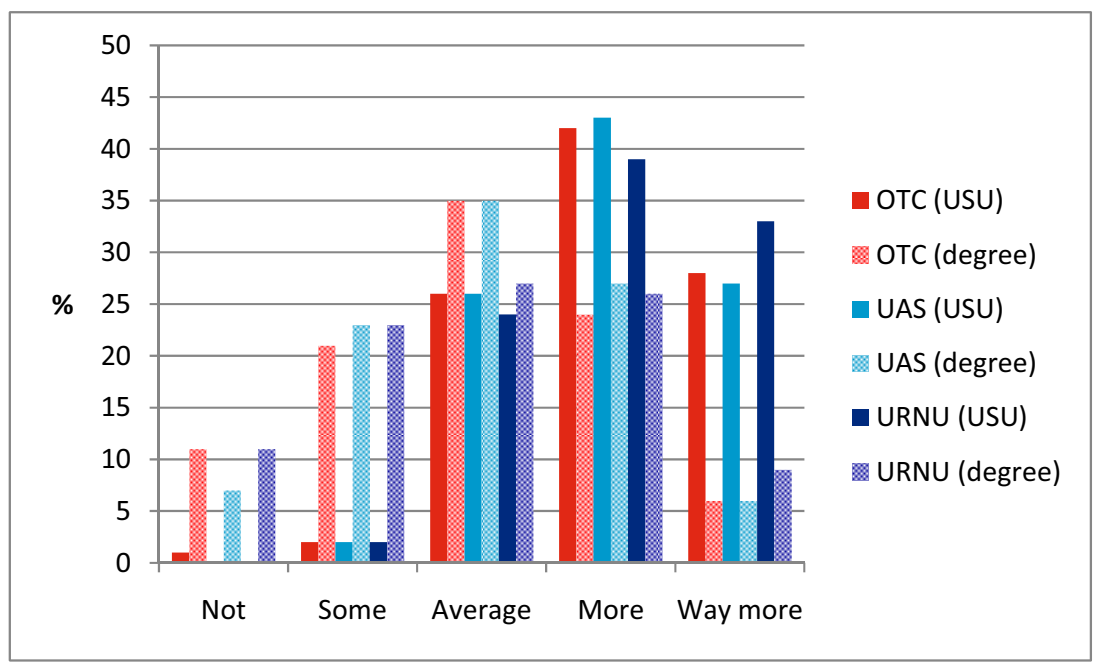

Figure 3.34: Teamwork: student evaluations of USU and university degree.

these skills, the exception is leadership, with higher proportions considering that they had had negligible or few opportunities for leadership development through their degree programmes. For all the interaction skills, student evaluations of the level of which their USU participation has helped them develop 
these skills show a marked skew to the right of each graph, indicating that a significant proportion consider that their USU experience has helped them both to develop these skills, and to do so to an extent which is more or considerably more than they had anticipated. Leadership is defined in the Newcastle skills framework as the ability to 'motivate and co-ordinate group members, taking responsibility for decisions and results. ${ }^{59}$ Although it is a graduate skill, it appears that a relatively small proportion consider their degree programmes to help them develop it. It is possible that in responding to this question, USU members are reflecting the influence of their USU training and the discourses through which it is framed during that training; note the emphasis on leadership highlighted in the mission statements for the units in Chapter 1. In other words, because students are both given training in leadership, and because those activities are explicitly flagged to students as contributing to their leadership skills, they are more likely to explicitly recognise it as a feature of their USU experience.

\subsubsection{Other skills}

We also included in the survey some questions about skills that are not included in the Newcastle University graduate skills framework. We were interested in knowledge of the armed forces (Figure 3.35), maturity (Figure 3.36), self-confidence (Figure 3.37) and social skills (Figure 3.38); a disparate set grouped here for convenience but speaking to rather different skill sets.

We would expect degree programme-derived knowledge of the armed forces to be low, and for expectations of the level to which the USU experience develops this knowledge to be both met and exceeded. For maturity, self-confidence and social skills, university participation again shows a normal distribution, and USU participation again appears to be both identified as responsible for generating this skill, and its development to a level that significantly exceeds expectations.

\subsubsection{Skills development and gender}

For some of the skills about which we asked our student respondents, there were noticeable differences between men and women in terms of the recognition of skills development and the level to which their expectations had been met or exceeded through USU participation. Figure 3.39 shows this data for self-confidence and Figure 3.40 for time management, disaggregated by gender with reference to USU participation.

${ }^{59}$ Details on the Newcastle University Graduate Skills Framework (2013) are available at: http://www.ncl.ac.uk/quilt/assets/documents/str-gsf-framework.pdf 


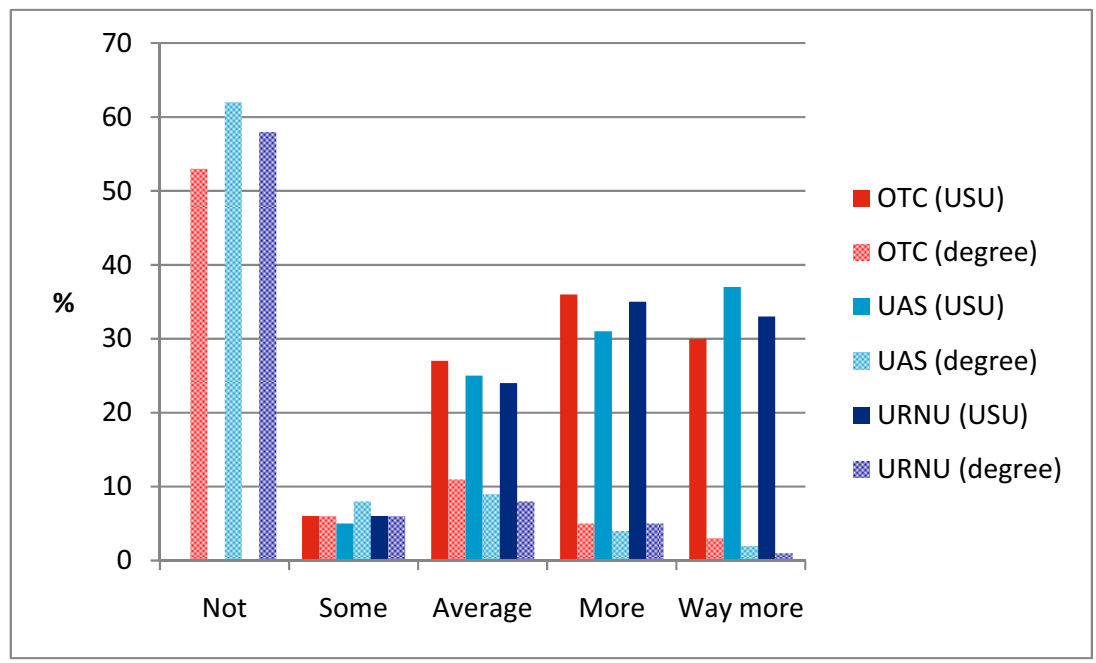

Figure 3.35: Knowledge of the armed forces: student evaluations of USU and university degree.

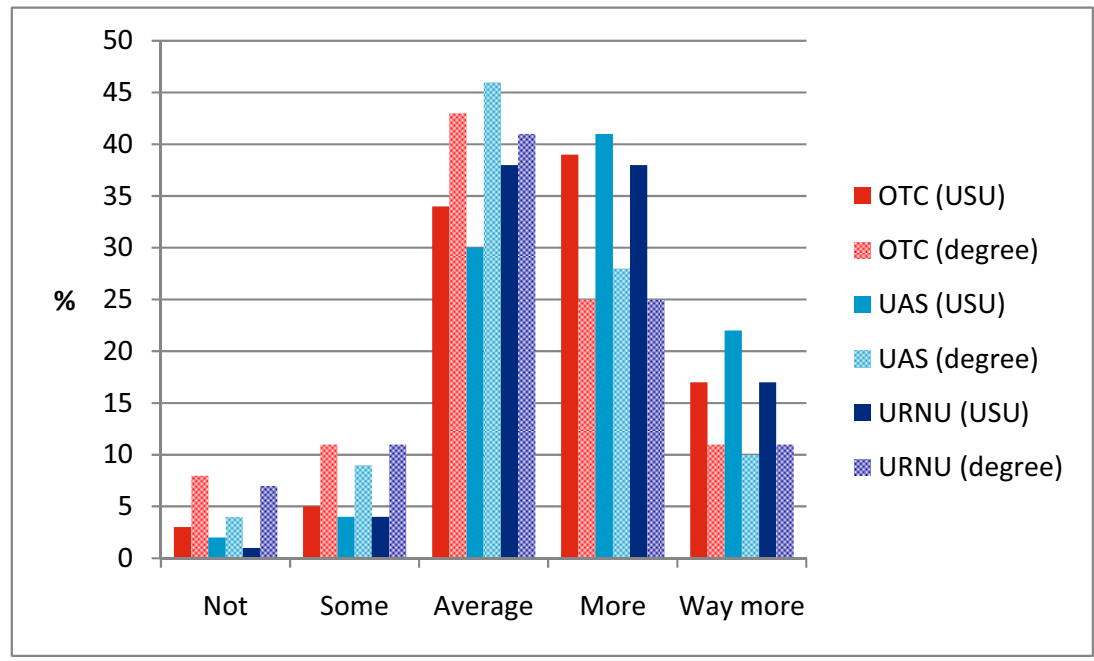

Figure 3.36: Maturity: student evaluations of USU and university degree.

Again, with a quantitative methodology, opportunities to explore with respondents the reasons for their evaluations are very limited, so there is no way of definitively explaining this gender difference. It may well be that the 


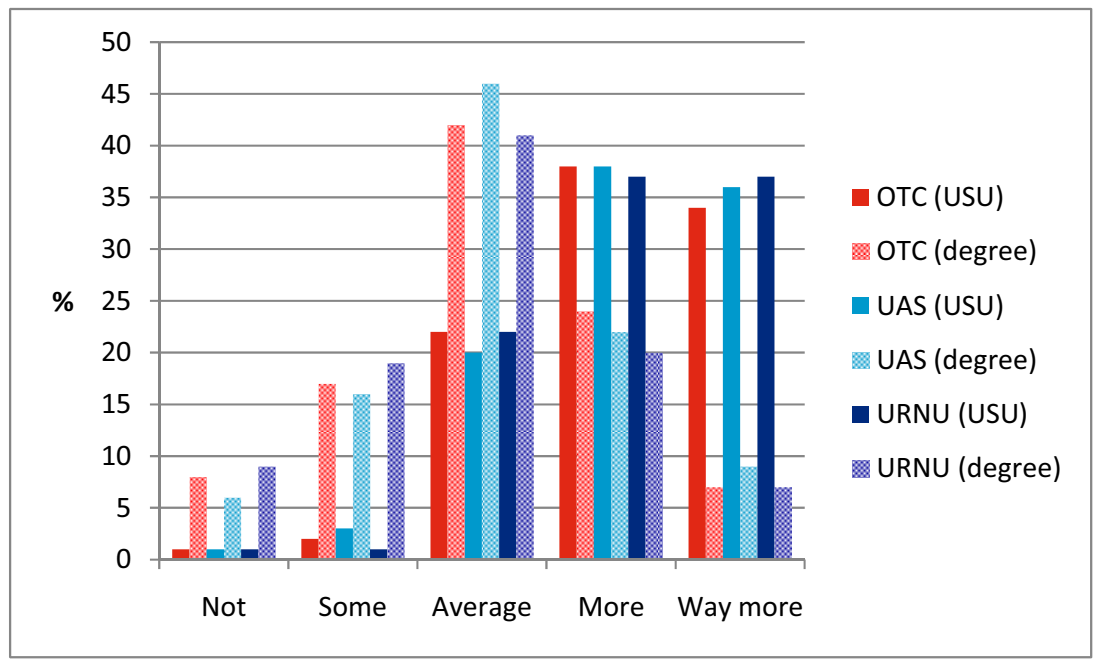

Figure 3.37: Self-confidence: student evaluations of USU and university degree.

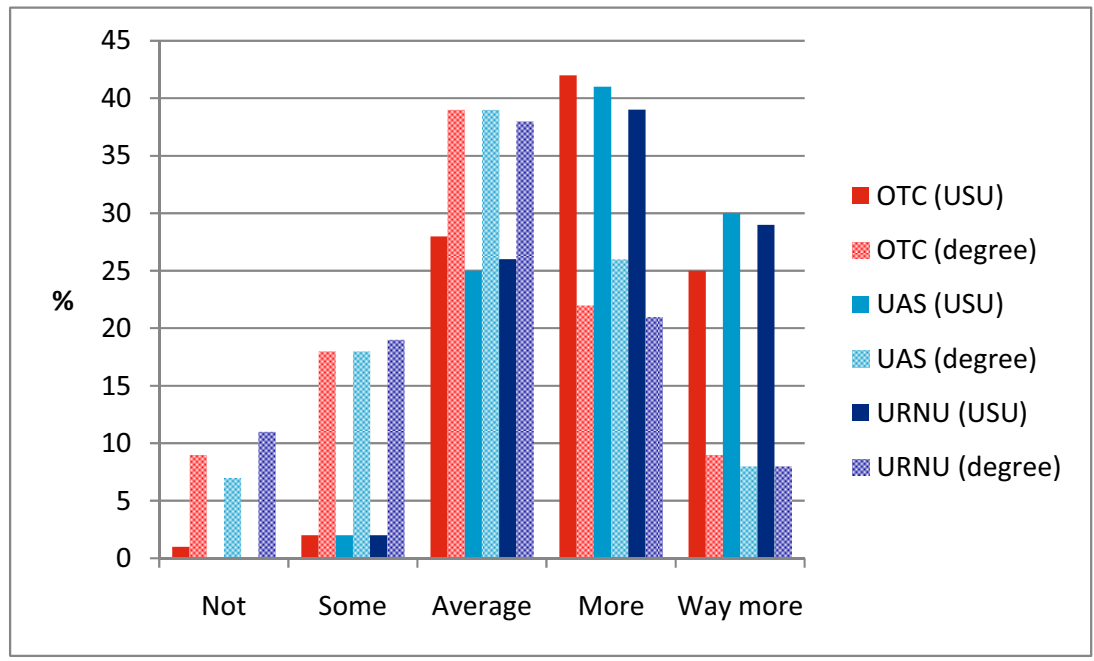

Figure 3.38: Social skills: student evaluations of USU and university degree.

female respondents to the survey were (for whatever reasons) more enthusiastic overall than the male. But what the data appears to suggest is that the expectations and anticipations about skills development for women in the service units exceeds that of men. 


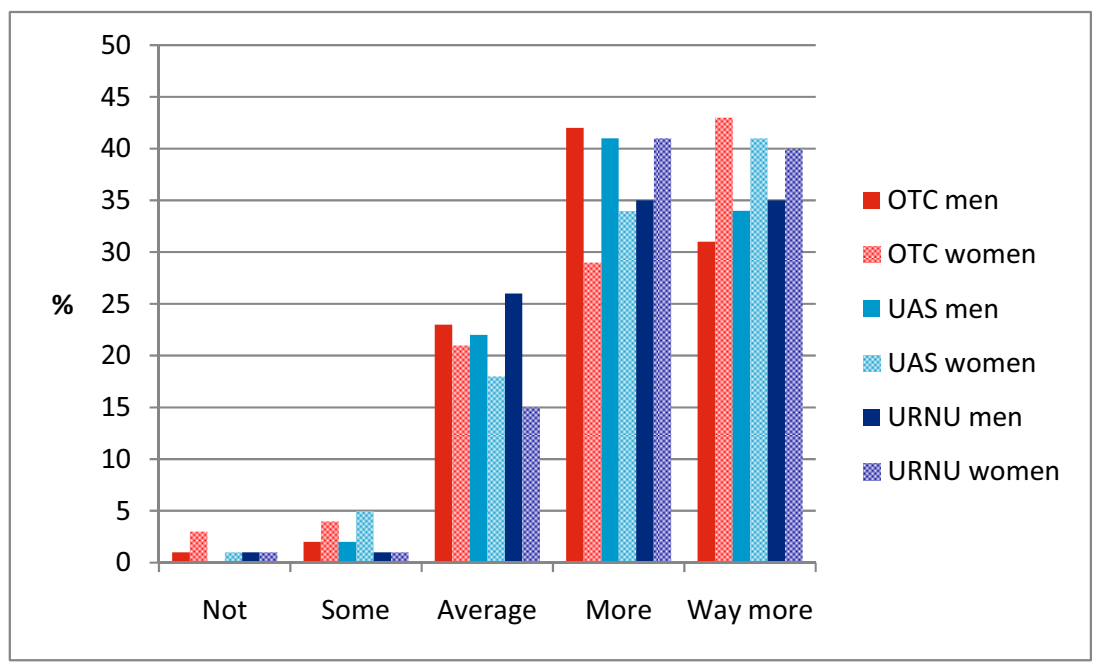

Figure 3.39: Self-confidence: assessments of USU skills development by gender.

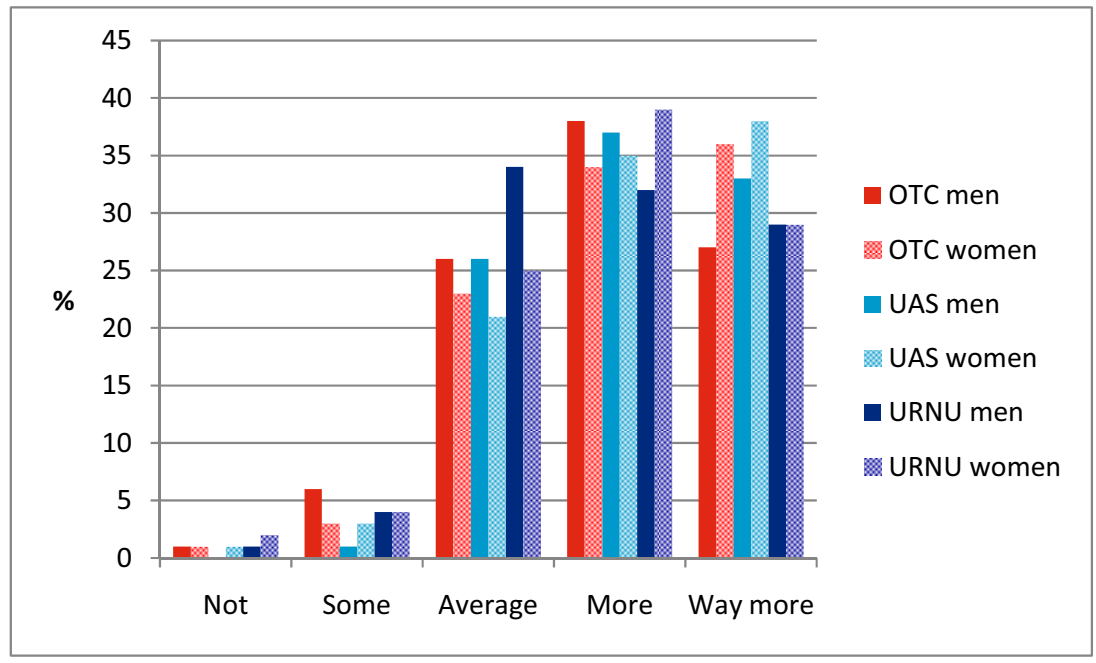

Figure 3.40: Time management: assessments of USU skills development by gender.

\subsubsection{Evaluating student skills development}

There are three contextualising points to make about the levels of skills development students perceive that they get through their USU experience and 
degree programmes, and the rates at which they evaluate them. The first is that we should remember that for the vast majority of students, their USU activities constitute a hobby outside the work of a university degree, work which is both intellectually demanding and often laborious. Although this kind of qualitative data capture cannot explore student understandings of the qualitative differences between their academic studies and their USU activities, it is likely that the former is seen as more mundane, even quite ordinary, compared with the latter which may be seen as more fun (and which certainly includes a considerable social element, evidenced from the qualitative comments in section 3.9 below). The second point, again not captured through this kind of methodology, is that it is possible that unit COs and others within USUs are extremely adept at communicating to students how and why particular activities that they undertake might provide them with skills development opportunities, and that this might happen to a greater extent than during the course of university studies. The third point is that the disaggregation of data above does not take into account the different degree subjects and qualifications being pursued by the cohort of students. It is highly likely that different subjects and qualifications include very different emphases in terms of skills training.

The final point, and this is significant, is that we asked students to engage with this fine-grained exploration of skills development only with reference to their USU experience and their degree programme experience. We did not ask student respondents to evaluate other activities using this same evaluation methodology, not least because of the range of possible activities and the difficulties of satisfactorily capturing such experiences in a reliable and comparative manner across this range. It follows that there will be a range of other activities that students undertake which also provide opportunities for graduate skills development.

We did, however, ask our respondents for a broad indication of whether the skills learned through their USU were also learnt from other activities. A total of $18 \%$ of respondents considered that they learned these skills nowhere else. Overall, 58\% considered that USU-derived skills were also developed through their degree programme, $33 \%$ through university sports activities, $18 \%$ through a union club or society activity, $18 \%$ through charity or other voluntary work, $26 \%$ through paid employment and 3\% through other activities. Figure 3.41 shows this data disaggregated by the three service units.

Students recognise to varying degrees the ways in which other activities beyond their USU experience inculcate many of the skills that they also recognise as receiving through their USU. We should be clear that we are not implying that the USU experience provides in some way a superior source for skills development for students. ${ }^{60}$ Our conclusions are more nuanced than this, suggesting

${ }^{60}$ For a more detailed discussion of other activities undertaken by students and other young people, and the skills development opportunities which this then generates, see: Baillie Smith, M. and Laurie, N. (2011). International volunteering and development: global 


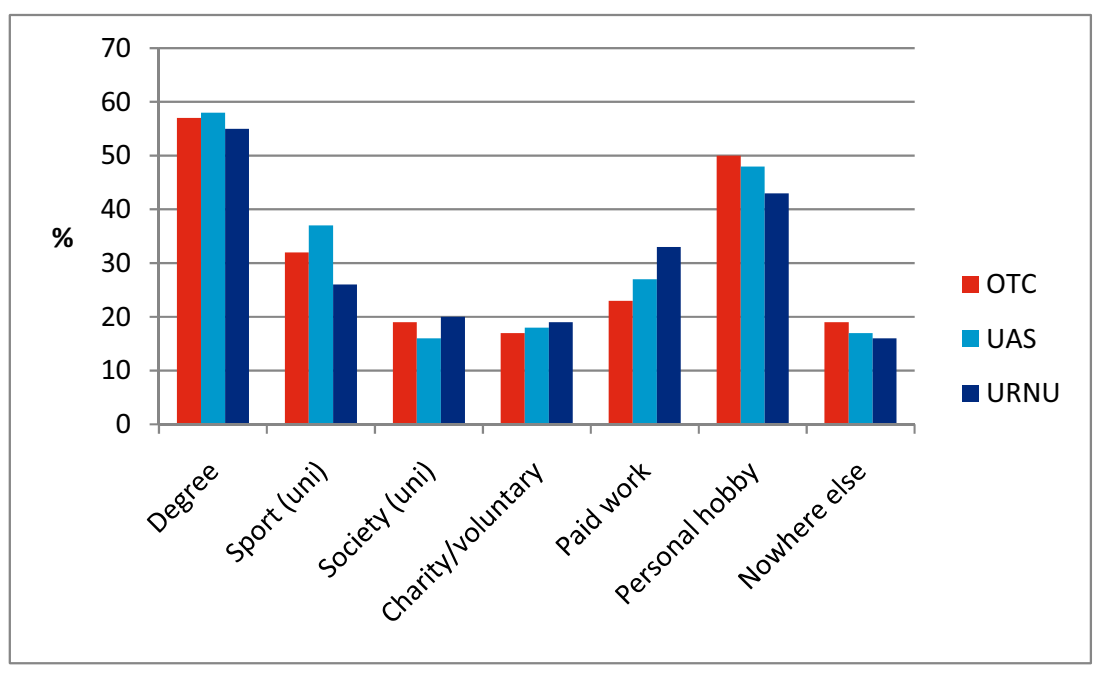

Figure 3.41: USU skills learned through other activities.

that the USU experience is one of many sources of skills, and that it provides a wide-ranging group of skills which students are adept at recognising. As we go on to explore in section 3.7 on seeking and gaining employment after graduation, and section 3.9 on overall assessment of the USU experience, it is the combination of skills and the applicability of those skills to the workplace which is seen as particularly significant by students.

\subsection{Progression through university}

We asked student participants whether being in a USU had helped them progress through their degree, and invited qualitative responses. This is a significant issue because of the time commitments USU participation incurs (something raised by both students and graduates), and the possibility that academic work might suffer because of USU commitments (something which commanding officers were keen to prevent). It is also significant because it had been suggested, anecdotally, by students to the research team prior to data collection that despite the challenges of competing commitments, participation in a USU

citizenship and neoliberal professionalization today. Transactions of the Institute of British Geographers, 36, 545-559; Jones, A. (2008). The rise of global work. Transactions of the Institute of British Geographers, 33, 12-26; Holdsworth, C. and Quinn, J. (2011). The epistemological challenge of higher education student volunteering: "reproductive" or "deconstructive" volunteering? Antipode, 44 (2): 386-405; Holdsworth, C. M. and Brewis, G. (2014). Volunteering, choice and control: a case study of higher education student volunteering. Journal of Youth Studies, 17 (2), 204-219. 
had a positive knock-on effect on their attitude towards their academic studies. The beneficial knock-on effects of positive experiences in general beyond academic work is well recognised in universities teaching contexts, and so it was thought to be interesting to evaluate this.

Students were asked whether their USU participation had helped them progress through their degree programme. Overall, $53 \%$ of OTC, $61 \%$ of UAS and $59 \%$ of URNU members said that yes, it had. The higher positive assessment from UAS and URNU members may reflect the closer match between degree subject studied and its actual or potential application in military contexts (examples would be engineering or medical degrees). Figure 3.42 shows this data disaggregated by length of time in service unit.

Some caution needs to be exercised with regards to Figure 3.42, because those with more than three years in the unit constituted a very small number in the sample. The basic point suggested here is that student evaluation of the assistance USU participation brings to degree progression increases over time in the unit.

We also asked respondents to explain their answer. Ideas included the development of skills through USU activities which were transferable to academic contexts (time management was the most frequently cited), the positive effect of having an activity entirely different from academic studies, the pay, the benefits of the social life, the increased ambition and wider horizons that the USU experience inculcated in some students, and subject-specific assistance. The following quotations are illustrative:

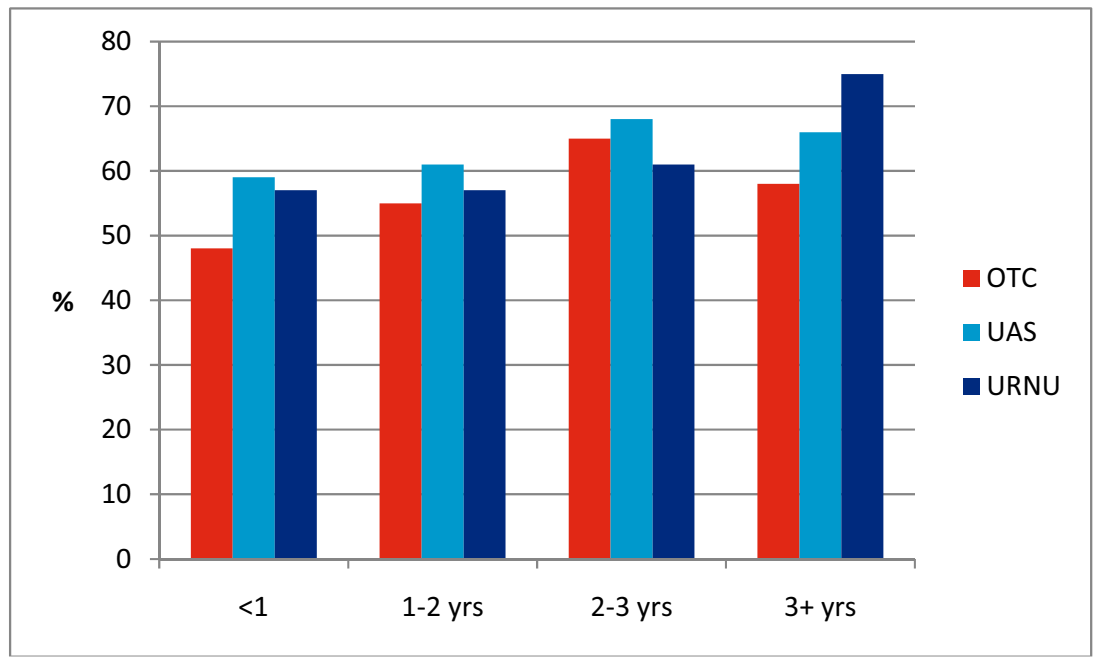

Figure 3.42: USU participation: positive effects on degree progression, by percentage. 
'Having not found my degree programme as challenging as I expected, OTC doubled my enjoyment of university and introduced me to lots of people who don't want to sit on a sofa all weekend. Getting out of the work bubble has made enjoyment of the work I've been given slightly more enjoyable.'

'I cannot stand university, I would have left by now if it were not for this.'

'I don't exactly enjoy my degree. EUOTC could be the main reason why I haven't left University. It's taught me that having a degree is good no matter what it is, so I am now determined to finish it.'

'Given me a breathing space to occupy my mind outside of the lecture theatre, at times it has indeed proven to be another burden similar to having another course module to learn and succeed in (MOD2), however, for the most part it has proved nothing more than a positive experience with much needed financial support when things have been tight.'

'Motivates me to get out of bed and work hard. If I can get up at 6am in the freezing cold then I can get up at 7am to go to the library'

We also asked respondents to the survey whether being in a USU had been detrimental to their progression through their degree. A total of $25 \%$ of OTC, $18 \%$ of UAS and $11 \%$ of URNU members said that it had been. In qualitative responses, prioritising of USU over academic work commitments was given as the explanation by virtually all respondents. Many also noted that this was a time management problem which they themselves had responsibility for and had failed to resolve adequately.

Respondents were also asked whether their USU activities could be used for credits towards their university degree. Overall, $72 \%$ said no, and an additional $23 \%$ said that they did not know. Amongst the 5\% replying 'yes' (88 respondents in total), responses included workplace learning or skills development modules where USU experience could be used as a case study (and was accepted as an equivalent to any other paid employment). One student mentioned that their university (University of Glasgow) included on their final marks transcript their MOD1 and MOD2 awards, although this was not part of the credit structure for the degree itself. Students also mentioned other institutional schemes where USU experience could be included in an award (but again, not creditbearing for degree purposes), such as: 'The Exeter Award', the 'ncl+ Award', the 'Plymouth Award', the Queen's University Belfast 'Degree Plus Award', the 'Bangor Employability Award', 'Sheffield Graduate Award' and the 'Ulster Edge Award'. The qualitative comments suggested that many students were uncertain about exactly what these awards constituted and how their USU experience might be used for accreditation. Qualitative comments also indicated student awareness of the utility of such awards for future job applications, alongside academic qualifications. 


\subsection{Career choices}

The relationship between USUs and recruitment to the armed forces is a complex one. The three armed forces have, historically, had different understandings of the utility and advisability of using units for recruitment. As Chapter 1 indicated, at present two distinct UK armed forces recruitment issues have brought USUs into prominence. The first of these is the need for the armed forces to recruit the right people, of the right calibre, for available posts in a context where the armed forces, as a graduate employer (in this instance), is struggling to compete for applicants in a competitive graduate recruitment market. The second of these is the expansion of the Reserves under Future Forces 2020 and the utility of the USUs for direct Reserves recruitment and training, an issue applicable to the Army and influential in the development of the OTRs.

The survey asked respondents for their views about potential future armed forces participation, in terms of their pre-university aspirations and their current career plans.

\subsubsection{Pre-university views on an armed forces career}

We asked respondents to select which of seven different options best applied to them in the time before they arrived at university, with options outlining successively greater levels of proactivity and commitment towards determining the armed forces as a career path. Inevitably, we are reliant on respondents' abilities to accurately recall their activities and plans in the past, with the usual caveats that this brings in terms of reliability. That said, some clear patterns emerge, as shown in Table 3.6.

\begin{tabular}{|l|r|r|r|}
\hline & OTC & UAS & URNU \\
\hline I never considered joining the Armed Forces & 15 & 10 & 20 \\
\hline $\begin{array}{l}\text { I thought about joining the Armed forces, but took no } \\
\text { positive action }\end{array}$ & 24 & 19 & 29 \\
\hline $\begin{array}{l}\text { I made inquiries about joining the Armed Forces, but took } \\
\text { no further action }\end{array}$ & 24 & 29 & 22 \\
\hline $\begin{array}{l}\text { I attended a recruitment event run by an Armed Forces } \\
\text { recruiting team, but took no further action }\end{array}$ & 12 & 12 & 7 \\
\hline I applied for university sponsorship & 5 & 15 & 7 \\
\hline $\begin{array}{l}\text { I made a formal commitment prior to going to university to } \\
\text { enter the Armed Forces on graduation }\end{array}$ & 10 & 3 & 3 \\
\hline Other & 9 & 11 & 11 \\
\hline
\end{tabular}

Table 3.6: Pre-university views on an armed forces career, by percentage. 
The proportion who never considered joining the armed forces is small, with distinctions evident between the three service units. A total of $10 \%$ of UAS members had never considered joining, indicating that $90 \%$ of UAS members had entertained at least in some way the idea of joining prior to university. Conversely, one fifth of URNU members arrived at university without having considered the idea of an armed forces career. Across the three service units, over half of student members had thought about a career, made inquiries or attended an event (60\% of OTC, $60 \%$ of UAS and $58 \%$ and URNU members).

The 'other' category ( $10 \%$ average across the three service units) provides some further insight into the range of decision-making processes, events, outcomes and circumstances which shaped students' motivations and plans prior to university. Qualitative explanations contained information about issues which had altered a previous decision to consider an armed forces career, including medical and fitness issues, the effects of defence restructuring and consequent removal of identified opportunities, failure to achieve a required set of qualifications or to get a place on a chosen programme (including at Welbeck, the Defence $6^{\text {th }}$ Form College) and the realisation that a career in the armed forces was not after all what they wanted.

Given that a significant proportion of service unit members indicated that prior to university they entertained the idea of joining the armed forces, this suggests that the university service units are recruiting heavily amongst people who had already positively considered the idea of joining the armed forces (however vaguely). This is potentially a group receptive to the idea of military participation, although it should be evident that the decision-making process around an armed forces career is a complex one involving a confluence of individual abilities, circumstances and aspirations, and the availability of advice, opportunities and placements.

\subsubsection{Student views on an armed forces career}

We were interested in whether unit participants become interested in an armed forces career whilst serving in units. We asked survey respondents to select one of 10 different options outlining ways in which that interest or intentionality, or lack thereof, could be expressed (see Table 3.7).

Those who selected 'other' and gave qualitative commentary indicated uncertainty about their future options with the armed forces. Only seven (of 201 comments) indicated specific factors (medical, career or circumstantial) which prevented them being able to make this decision. The remainder indicated their uncertainty, indecision or their wish to keep their options open, or suggested that they had not considered an armed forces career as an option, as the following examples illustrate:

'I had thought about joining the armed forces but was not seriously considering it as I felt I had no idea what it'd be like and wouldn't want to 


\begin{tabular}{|l|l|l|l|}
\hline & OTC & UAS & URNU \\
\hline $\begin{array}{l}\text { I was intending to join the Regular armed forces prior } \\
\text { to joining my USU, and still am. }\end{array}$ & 35 & 45 & 27 \\
\hline $\begin{array}{l}\text { I was intending to join the Reserve armed forces prior } \\
\text { to joining my USU, and still am. }\end{array}$ & 5 & 2 & 2 \\
\hline $\begin{array}{l}\text { I was not intending to join the Regular or Reserve } \\
\text { armed forces and still am not. }\end{array}$ & 8 & 7 & 13 \\
\hline $\begin{array}{l}\text { I was intending to join the Regular armed forces but am } \\
\text { now intending to join the Reserve armed forces. }\end{array}$ & 10 & 6 & 6 \\
\hline $\begin{array}{l}\text { I was intending to join the Reserve armed forces but am } \\
\text { now intending to join the Regular armed forces }\end{array}$ & 3 & 1 & 1 \\
\hline $\begin{array}{l}\text { I was intending to join the Regular armed forces but am } \\
\text { no longer intending on joining any armed forces. }\end{array}$ & 3 & 5 & 5 \\
\hline $\begin{array}{l}\text { I was intending to join the Reserve armed forces but am } \\
\text { no longer intending on joining any armed forces. }\end{array}$ & 1 & 0 & 2 \\
\hline $\begin{array}{l}\text { I was not intending to join the armed forces but now } \\
\text { intend to join the Regular armed forces. }\end{array}$ & 9 & 13 & 12 \\
\hline $\begin{array}{l}\text { I was not intending to join the armed forces but now } \\
\text { intend to join the Reserve armed forces. }\end{array}$ & 16 & 8 & 16 \\
\hline Other (please specify) & 9 & 12 & 15 \\
\hline
\end{tabular}

Table 3.7: Student views on an armed forces career, by percentage.

commit myself when I had no idea. I am now seriously considering joining the armed forces, although have not yet completely made up my mind.'

'I was not intending to join the armed forces, but am now considering joining the Reserve armed forces (part-time) or the regular armed forces. I think intend is too strong a verb for my current situation.'

'Intending is perhaps a too strong a word, I was indeed considering whether a career in the military would be for me and have used the OTC as an opportunity gain insight into what would be involved.'

'Before university I was interested in joining the RN but not fully convinced I could, after joining the URNU I know the areas I need to work on however I still haven't decided on whether I want to join the reserves or the regulars.'

Table 3.7 raises some significant points with regards to debates about USUs and armed forces recruitment. We can conclude, first, that there exists in the USUs a significant proportion who express an intention to join the regular armed forces upon graduation: crudely, a quarter of URNU, a third of OTC and nearly half of UAS members indicate this. There is therefore clearly an identifiable pool of potential armed forces recruits within the service units. The differences between 
service units reflect the higher proportion of UAS members considering RAF careers proactively prior to university (see Table 3.6) who are potentially using the UAS as a pathway to that career. It is clear that a much lower proportion arrive at university with the intention of joining the Navy. It is also clear that a proportion of students arrive in their units with no intention of joining the armed forces, but who subsequently change their minds (9\% of OTC, 13\% of UAS and $12 \%$ of URNU members). Second, a small proportion either had no intention of joining and still did not (8\% of OTC, 7\% of UAS and $13 \%$ of URNU members), or changed their minds and decided against joining the Regulars or Reserves after graduation (4\% of OTC, $5 \%$ of UAS 7\% of URNU members). Third, there is also a small proportion of students who had either intended to join the Regulars but are now looking to the Reserves (10\% of OTC, $6 \%$ of UAS and $6 \%$ of URNU members), or had no intention prior to university of joining the armed forces, but now intend to join the Reserves (OTC of 16\%, UAS of 8\% and URNU of $16 \%$ members). Qualitative comments indicate that the Reserves features prominently amongst those still trying to decide on future involvement post-graduation with the armed forces. This point will be of interest to those with strategic responsibility for Reserves issues and recruitment. We return to the issues of USUs and armed forces recruitment in Chapter 7.

\subsubsection{General impact on post-graduation career choices}

As well as asking explicitly about intentions with regards to armed forces participation prior to and during university, we also asked student USU members whether joining a USU had impacted on their future career choices. A total of $67 \%$ of OTC, $73 \%$ of UAS and $65 \%$ of URNU members said that yes, it had. When this data was disaggregated by gender, $72 \%$ of female OTC participants said 'yes' (compared with $66 \%$ for male participants and $67 \%$ for OTC members overall). In the UAS and URNU, the proportion of women reporting that being in an USU had impacted on their career choices was lower than that of men (71\% for women compared with $75 \%$ for men in the UAS; $63 \%$ for women compared with $66 \%$ for men in the URNU). We can speculate that the OTC experience may be more influential in shaping women's future career choices than the other two services, or that the broader range of degree subjects (and lower proportion studying vocational or applied subjects) in the OTC grants greater flexibility for OTC participants.

We asked respondents to explain their responses. Students mentioned how USU participation had opened up the idea of a military career, as the following examples illustrate:

'More interested in joining the armed forces.'

'I am now considering a career in the military, whereas before I knew little about the career opportunities.' 
'Before joining URNU I had very little knowledge on the things they done during peace time and conflict, after being involved for a few months I have started to realise that there is plenty of opportunity for me in the Royal Navy. Having talked to visitors to our unit has given me a chance to gather knowledge on the skills and lifestyle in the armed forces.'

'I now consider choosing an Army career as I know there are so many opportunities for language students such as myself.'

'When I first joined I was 70\% sure that I would not be joining the Armed Forces, however, now that I have been in WUOTC for around 10 months I am now around $60 \%$ sure that I WILL join the Armed Forces at some point after my degree is finished.'

'I didn't believe I would be able to cope with all the physical and mental demands of military lifestyle and therefore ruled out officer as a career choice - I now see that with determination it is actually a career I could pursue and am interested in.

USU participation also consolidated existing aspirations to join the armed forces:

'When I came to university, I was considering a career in the military. Being in the UOTC has confirmed this for me.'

'It has widened my future career ideas, I have long had an interest in the military but didn't know the diverse range of jobs that were available until joining NUAS.'

'It has increased my desire to join the Air Force.'

'I'm joining the Army as I have realised that the forces are the place I really want to be. Always considered a military career but never seriously until I had been in the UAS for a while.'

'I've applied for the Officer selection board, I don't think I would have had the confidence to do this on my own.'

'Made me more determined to apply to join the regular army than before my time at university.'

Students identified how the experience enabled them to make an informed choice, giving a fuller insight into what such a career might provide:

'Before joining I was considering joining the Armed Forces. Having now been in the UAS for 4 years and been able to see the inner workings of forces life, I was able to make a more informed decision on whether or not I would want to join the Armed forces.'

'The exposure to the armed forces has helped me question whether or not a career within them would be a possibility. After much thought and looking at different aspects of potential military careers I arrived 
at a decision I would not have been able to make without experiencing the USU'

'It has made me both more interested but also more wary of joining the armed forces. The activities and opportunities given to me have made me aware of the benefits of a career in the military, however it has also highlighted elements of the military that do not appeal.'

'It has given me insight into what life in the armed forces would be really like.'

Participation can confirm a suspicion that a military career would not be suitable for that individual, however much they might enjoy the USU experience:

'I joined UAS unsure if I would like to join the armed forces after my degree, but after several months I now know that whilst I have the utmost respect for the military, the lifestyle is not for me and I would prefer to do something related to my degree; although I have not ruled out reserve forces, i.e. TA.'

'I've emphatically ruled out any trifling consideration of joining the Army'

'Whereas before I'd thought about joining the navy, but couldn't risk it as a career in case it wasn't for me. I now know that it's not for me. I'm more naturally suited to civilian roles.'

Participation can also raise awareness of a range of opportunities with the armed forces of which they had hitherto been unaware;- we have noted above the proportions (crudely, a quarter of URNU, a third of OTC and nearly half of UAS members) who were intent on a career in the armed forces whilst students. In identifying USU participation as impacting on future career choices, these students identified how the experience has expanded awareness of occupational choices available to them within an armed forces career:

'It's made me consider different branches in the military that I hadn't previously explored that may be more suited to my skills.'

'It has opened my eyes to the specifics of the job roles I strived for, and helped me understand the nature of the roles better. This caused me to consider a career in the Intelligence branch (something I would never have approached beforehand).'

'It has shown me the variety of military careers available alongside the pilot career I was considering.'

'I am currently at medical school and being in the UAS has made me consider a career in the forces post graduation in emergency medicine.'

'Knew I wanted to join armed forces and experiences through the OTC have helped me narrow down my choice of regiment/role. For example, talks from serving engineers or signals soldiers have been a 
great insight into the different roles within the army. The highlight being the visit by 21 SAS.'

'When I joined the UAS I was vaguely considering joining the RAF but my perception of the day to day job of an Engineering Officer did not appeal to me. Through my time in the UAS I have learnt more about the role of Junior Engineering Officers and am now seriously considering a career in engineering in the RAF.

'I was fairly sure I wanted to join the navy after Uni but am now set on it. Though not in the same role: I was planning on joining as an engineering officer but am currently applying for warfare.'

Comments on career choice changes as a result of the USU experience revealed how participation can be significant in raising awareness opportunities with the Reserves, even if a full-time career was not considered feasible:

'I am still undecided between being a regular or TA medic but the OTC has me firmly convinced that the forces are a thing I would really like to be a part of in some capacity through my career'

'Deciding between military and civilian life will be tough. Will probably end up in reserve forces.'

'It has encouraged me to join at least the reserve forces.'

'I was interested in the forces before joining, however I originally wanted to join the regular army but OTC has caused me to reconsider to joining the TA instead.'

'Yes - made me reconsider whether I wanted to join the RAF - very good insight into life in the forces and also into how we can be reservists and balance it with a civilian career. I am now considering joining as a pilot.'

'I originally wanted to be part of the RN, but now I would like to enter into civilian employment whilst keeping up my participation in the reserves.'

Participation also raises awareness of opportunities in sectors and occupations related to those encountered through involvement with the armed forces:

'Considering a career at sea. Navigation has been exciting and fun endeavour.'

'It has made me think that I am more capable than I thought, encouraging me to apply for a post-grad medicine course after my undergraduate degree.'

'I guess it's made me aim higher. My degree isn't very technical, but the skills I have gained in navigation etc have highlighted that I have skills in these areas. I will be doing nothing with the military though.' 
'I will likely not join the armed forces after graduating but it has improved my graduate prospects in civilian areas and strengthened my interest in working in defence (e.g. for BAE Systems, Thales etc.)'

Participation raises students' awareness of what they might want to get out of a job when they graduate:

'I have never and still don't want to join the armed forces after graduation, however being in the OTC has shown me that I would not be able to cope with a desk or lab based job.'

'It has shown me that there is more out there than just sitting behind a desk.'

'It's confirmed that I'd ideally like a career in public service.'

'I now know I will not want to go into active service in the armed forces. However I also will be more able to support ex-service personal in work (I think!).

It is also instrumental for many in developing personal awareness about their abilities, their confidence and the development of skills that they credit to USU participation:

'I feel that I can aim really high in graduate jobs and get the top positions as the UAS has given me a lot of confidence.'

'I believe it adds another string to my bow and adds weight to my $\mathrm{CV}$ when applying for new job roles, demonstrating that I am a team player with social skills and the drive to do things beyond my university degree.'

'As mentioned above, I now am aware that I am more capable than I previously realised. I now want to lead, and preferably in a sector or career that is dedicated to helping or defending the population, whereas I previously was never truly going to push myself.'

The significant observation here is about the positive value of the USU experience in developing, consolidating and confirming student perceptions about the possibility or otherwise of a military career. The experience offers a noobligation mechanism for students to explore the option. This has long been suspected by those responsible for the USUs; what the survey data confirms is the range and nuance of student perceptions about career choices. This information may possibly be of use to recruitment strategies for the armed forces. It may also be useful for USU recruitment purposes, because it suggests the value of the service unit experience to students in helping them develop their thinking about career options in general, and not just around the armed forces. 


\subsection{Seeking and gaining employment after graduation}

We were interested in exploring whether, and how, USU participants understood their USU experience in relation to their efforts to obtain employment after graduation. A total of $87 \%$ of OTC, $94 \%$ of UAS and $88 \%$ of UNRU members answered affirmatively when asked whether being in a USU would help them with getting a graduate job. About one third of the whole sample had already applied for a graduate job at the time of the survey. We elicited qualitative comments to explore this understanding of value in the labour market in more detail, and respondents had much to say (1,777 individuals provided comments). The most frequently cited reason why students thought being in a USU would help them get a graduate job was the transferable skills:

'Where do I start? The list of transferable skills goes on forever, and if an interviewer ever asks for an example of a situation that you have never even thought about, it won't take long to think of something you did on the UAS. The tick-list above [on the survey - see section 3.4 above] shows what skills the UAS has developed and I think most employers would value a person with just a couple of those skills, let alone the majority of them.'

The most commonly mentioned skills were leadership, time management, teamwork and presentation skills, and these were anticipated as useful on a CV or job application, or to discuss at interview:

'On a basic level, it gives us experiences that we can use to demonstrate our skills. "Have you ever worked in a team" - I not just worked with one, I lived with one.'

'The transferable skills with my time spent with the Air Squadron is second to none, I do not think there is anything quite like it to improve your personal skill set in such a short space of time at university.'

'The activities actually directly helped me get a year-long internship in Formula 1 Engineering, this was pretty much all we spoke about in my interview. In addition the communication skills gained in the Air Squadron helped me portray myself that much better.'

USU experience was thought to provide wider knowledge of the working world to which those transferable skills could then be applied:

'The structure within the armed forces of rank and hierarchy is not dissimilar to that of the world of health care, especially within emergency medicine and in the hospitals. The attitude of respecting your superiors, time management and being put into pressured situations are all transferable skills.' 
'It already has done. Have gained a job in the oil industry based on experience and proven skills learnt from the URNU'

'I am going into the field of civil engineering where leadership and team work are essential, and by being a part of the OTC I will have shown that I display these traits.'

The additional qualifications that USU participation could often lead to were valued as part of the package of skills the experience was understood to bring:

'It already has helped. I was awarded funding to do a $\mathrm{PhD}$ and in the interview they were impressed with the range of qualifications and experience that I had which has directly come from the OTC.'

'CMI qualification in management and leadership is beneficial and a lot of the qualities employers look for such as teamwork and leadership can be shown through experiences in the OTC.'

The students surveyed were very confident of their abilities to use their USU experience to confirm their skills and thus to demonstrate their employability:

'Even just for sake of saying "This one time on summer camp [...]" during an interview, would aid me in getting a job.'

'I have not had a single interview question that I would not be able to answer with an example of something that has happened to me during my time at the UAS.'

Given the competitive nature of the graduate labour market, it is unsurprising that students display this level of confidence; the USU experience suggests to students that they have additional qualities and experience beyond their academic qualification.

The military skills developed in the USU were, naturally, recognised as valuable to those seeking a military career following graduation, being seen as an 'obvious leg up into the military', 'sure to encourage a military selection board':

'The skills it has taught me will increase my chances of passing AOSB.'

'Hopefully being in the URNU will give me a better insight into the application process for joining the Royal Navy so I will be as prepared as possible, therefore potentially have a good chance of gaining the job I would like.'

'RAF selection looks favourably on having been a member of the UAS. The personal skills also aid the application and selection process.'

There was perceived value to gaining employment in the personal attributes and abilities the USUs were understood to inculcate. Increased self-confidence was frequently highlighted, which was stated by one member to have drastically 
improved their interview technique. Being in the unit was thought to show reliability, an ability to work hard, a proven ability at problem-solving and personal maturity:

'Better than a standard job - so many skills are developed such as team work, leadership, conflict resolution, that I think make you more employable. It brings up a lot of questions in an interview, from experience, and allows you to provide situations where you have coped with stress etc. Confidence in ability helps too.'

'SUAS has made me a more attractive all-round candidate to potential employers as a result of my personal development.'

'I have become much more assertive and career focused since joining the OTC. I also feel that the staff have been instrumental in making me more aware of my strengths and weaknesses, something that can only aid my career.'

'I believe that the USU participation has helped me to develop knowledge skills and experience which surpass anything which is readily available from one club or society at university. My CV has been a struggle to fit onto just two pages, using the smallest viable font and the most concise written English. For that reason, I would say that the USU will most certainly be a positive focal point during any graduate job applications.'

In a highly competitive graduate labour market, this use of the USU experience was thought to make applicants stand out and give them a head-start over their peers:

'There are a lot of graduates every year, the USU experience can show employers that I am not like the average student; drinking, parties and the normal things students do in their free time. Instead I spent my time making new friends, improving most everyday skills in industry from writing skills, problem solving to teamwork and delegation skills.'

'I am likely to get a 2:i, and the skills, which OTC demonstrates that I have, will help me (in addition to other extra-curricular activities) to stand out from the rest of the 2:i crowd.'

Students perceived that employers were looking for additional attributes and indications on a job application:

'Many employers look for outside activities from university'.

'It has made me much more employable as companies like to see that you're not just about your degree but also about your extra curriculars as well, OTC has definitely made me massively more employable and is the only reason I got such a good graduate job.' 
'It shows that we did something productive in our time at uni, rather than just drinking/clubbing etc.'

Students themselves have an understanding of what they think employer perceptions are, due to information from careers advisors, their degree programme and also very evidently, by USU training staff. Of those who had applied for a graduate position, a small proportion ( $3 \%$ overall) said they had sometimes omitted their USU experience from their CV or application; $97 \%$ had always mentioned it. USU members in Northern Ireland were sensitive to the security issue and were cautious about sharing information about their involvement on CVs (and, for one student, with family and friends).

Several students mentioned their concerns that by talking about their armed forces activities, an employer might consider them more committed to an armed forces career than the job for which they applied:

'I applied for a summer internship for a marketing firm and it seemed like they thought I was too involved with the armed forces so they did not want to invest their time and money in me. They did not specifically state this though. I subsequently omitted my USU experience from marketing applications (or at least downplayed it).'

Students were also asked about whether they were asked about USU experience in interviews, and individuals mentioned that they discussed this in response to questions about their competency for specific jobs or roles. Some employers were thought to be aware of the skills development aspect of the USU experience, as part of awareness of the armed forces brand:

'Whether being in a USU is relevant to my graduate job or not, I think the skills an employer believes I have gained from being in one will promote my chances of being employed.'

'The OTC is a respected institution that employers know provides you with valuable skills such as teamwork, communication, confidence and problem solving. Being a part of it shows that I am a balanced, sociable person that can add to the community of a business as well as its market value. I believe that in an employer's eyes it is a welcome addition to my CV.

'Two of my close friends that have left the UOTC managed to walk into very good job positions at an oil company in Aberdeen solely on their involvement with the UOTC whilst at university. Many companies' values correspond closely to that of the British army and being an active member of the UOTC sets you apart from the rest as being that bit more mature and having the discipline and drive to settle into a hierarchical system such as the workplace that many other students don't have yet.' 
'I have experience which very few people will have from their university years. Furthermore, the RN is recognised as a world class "employer" and therefore time spent with them will be taken far more seriously than say time with a standard university society'.

There was recognition, though, about the limits to employer understanding:

'The transferrable skills are excellent HOWEVER it requires people with a knowledge of the TA/UOTC to be in a position to hire those people with experience in the TA/UOTC.'

'This could be a yes/no, depending on my job and the sensitivity of such an organisation - in Northern Ireland does make this difficult to use on a CV'

'[Being in a USU has helped] but not to a great extent since I don't think that most companies have a very good idea of what USUs are.'

'The transferable skills leant are highly valuable. I understand that some companies and organisations (i.e. Amnesty International) may not look at candidates with military experience so favourably. However the other opportunities made available to you career-wise through the OTC, are far more valuable than being overlooked by a minority of companies.'

In conclusion, student survey respondents were enthusiastic about the skills generated through their USU experience, with $90 \%$ overall considering that being in a USU would help them get a graduate-level job. Note that for many this is perceptual rather than proven. We also asked students whether being in a USU would help with getting promoted in a graduate job. The respondents were more cautious on this, with $69 \%$ of OTC, $74 \%$ of UAS and $67 \%$ of URNU members confirming that they thought it would, primarily on the grounds of the transferable skills they would bring to employment. The qualitative comments indicate greater caution here, both because of the lack of direct experience ('Having not been employed in a graduate job how could I possibly know?'), but also because of recognition that the experience of actually doing a job would be the primary factor.

\subsection{Opinions about the armed forces}

The survey asked students directly whether their experiences since joining a USU had affected their view of the British armed forces by being asked to select one of five basic statements which best described them. A tiny number (seven respondents) reported that their view remained unchanged and negative, and $1 \%$ reported their view had changed and was now negative. This is unsurprising; USU participation is not compulsory and if students do not like it (because, for 
example, of negative views of the armed forces), they will leave. A total of $77 \%$ overall reported their views as unchanged and positive, and $15 \%$ reported their views as changed and now positive. Of the $6 \%$ who selected 'other', we asked for further clarification; what emerges from these comments is the idea that participation in the USU provides a more nuanced view of the armed forces:

'Mixed. Changed with a more positive view on the regular army but with a more negative view on the Territorial Army'.

'Changed. Gained a lot of insight and definitely a positive view of the organisation as a whole, I have a lot of respect for what they do, but through the USU have actually been put off joining the military. So both positive and negative.'

'Changed and is now ambivalent. Before university, my view was positive, but increased exposure has made me sceptical about certain things: I still feel positively about the Forces on the whole, but I experienced a lack of morale in the Fleet that I found shockingly low.

'Overall I am very positive about HM Armed Forces however having been to university and studied a social science I am now more acutely less favourable of current UK foreign policy. This is something not generally discussed in URNU but something I feel very strongly towards having developed my critical thinking skills at university.'

'Whilst I remain overwhelmingly positive, the OTC has shown me some of the flaws and failings in the Army, and has also (believe it or not) made me more open-minded regarding opposition to some of the Army's activities.'

'My opinion of the forces overall has not changed, but some of the people in positions of superiority have failed to meet my expectations.'

'I had mixed opinions of the Army when I first joined USU, I was very supportive of my brother so I had a positive opinion in the regard. However, I disagreed with the wars in Afghanistan and Iraq which painted the army in a bad light. Since joining the OTC I have come to understand and accept that the Army merely does what is told to do by the government so is not responsible for their decisions.'

'For the Armed Forces as a whole, it has made me realise that it is not nearly as professionally run as the civilian sector thinks at all and can be quite haphazard. At times the processes it uses to make decisions are overly bureaucratic, have a near dogmatic refusal to listen to common sense and are foolishly arbitrary. However my opinion of the Navy has greatly improved. Previously I thought it did nothing/ next to nothing. Now I know that is resolutely not the case.'

In conclusion, USU participants have a positive view of the armed forces. There is nothing particularly unsurprising about this: because participation is voluntary and because USUs are armed forces organisations, those who have or develop 
negative views of the armed forces on the basis of their participation to an extent where USU participation becomes untenable will leave. What is significant here is our suggestion that those who participate in the armed forces and who are thus exposed to the forces may feel better able to provide an informed explanation for their assessments, positive and negative, of the armed forces. This idea is explored further in Chapter 4, where we explore graduate views towards the armed forces.

\subsection{Overall experiences of university armed service units}

The survey asked students to give an overall assessment of their USU experience. Across the three service units, $90 \%$ rated their experience as 'mostly positive, $1 \%$ of OTC, $2 \%$ of UAS and $2 \%$ of URNU members rated the experience as 'mostly negative', and $9 \%$ of OTC, $9 \%$ of UAS and $8 \%$ of URNU members rated the experience as a 'mixture of positive and negative'. Qualitative responses (1,788 were provided) allowed students to explain their answer.

\subsubsection{Positive aspects of the university armed service units experience}

It is unsurprising that most students rate their experience as mostly positive: with the exception of the small numbers who are obliged for reasons of sponsorship to participate in a USU, participation is entirely voluntary. Those who feel they get something from their participation (which will be specific to each individual) that they feel is positive are, we suggest, likely to rate their overall experience as a positive one. Although quantifying responses (through postsurvey coding) proved impossible because of the range and combination of responses and ways of expressing ideas, certain explanations stand out.

The USU experience is fun ('serious fun'), enjoyable and provides social opportunities to make friends, meet other people with shared interests and participate in the camaraderie of the unit. Comments include:

'Adding to my university experience through socialising, learning skills, gaining qualifications, supplementing student income and gaining perspective on the armed forces.'

'Excellent chance to meet people, encourages an active and organised lifestyle, informs about army life culture; and is a lot of fun.'

'Fantastic experience, meet new people and develop new skills, get out of the university bubble.'

The utility of the experience in providing new or different opportunities or opportunities not available elsewhere to undertake specific activities, was significant:

'Amazing opportunities which are not provided by any other society at university. Couldn't think of university without it'. 
'Bristol UOTC is an amazing organisation, and has provided me with outstanding opportunities to gain an insight into an armed forces career, I have had the chance to participate in events and venues unimaginable to most of my course peers at university'

The idea of the experience providing a challenge was also clear, in the sense of an individual facing and having to overcome challenges posed by new situations and experiences, in the sense of being pushed to achieve things, in the sense of understanding the value of a challenging situation (even if it had not been fun at the time) and in the sense of achievement this generated. Related to this were perceptions of the experience in enabling personal development, and students included comments about learning to take responsibility, and their increased self-confidence, self-knowledge and self-awareness:

'Any negative aspects e.g. punishments for own poor personal admin or PT in bad weather are all good for personal development and character. Apart from these I haven't had a bad experience in the OTC.'

'Enjoyably challenging - it has opened doors and showed me my potential.'

Getting physically fit, participating in sports and enjoying the practical activities and the military training were significant:

'I get paid to get fit, have fun and make great friends - what more could I want?'

A great number of responses mentioned the utility of the experience in terms of pay, the gaining of qualifications, the development of skills in leadership, teamwork, time management and other transferable skills, and echo the assessments of skills made by students in response to other questions in the survey. Respondents also discussed their increased knowledge, understanding and appreciation of the armed forces, including the utility of the experience in considering an armed forces career (which included a perceived advantage in officer selection).

In a separate question, students were asked whether they would recommend joining a USU to other students. A total of $94 \%$ of OTC, $96 \%$ of UAS and $98 \%$ of URNU members said that they would.

\subsubsection{Negative aspects of the university armed service units experience}

The negative issues raised primarily concerned local organisational issues around unit administration and management, bureaucracy, lack of communication and the time spent waiting for things to start. A small number mentioned the time commitment unit participation required, including travel time 
to units. There were a small number of comments about the specifics of the organisation and delivery of the training syllabus associated with the change in one unit to an OTR. Note that the survey coincided with a time of change in this unit:

'Enjoyed my time, but often it seems that my unit cannot decide whether it wants to be a TA unit or a youth club and often strikes the wrong balance. It can be frustrating as certain individuals and sub units appear more valued than others.'

A small number of comments were critical of the attitudes of other students, including relating to excessive drinking and the social attitudes of students from different educational institutions within a unit. A small number also mentioned casual sexism within units, evident through derogatory comments towards women.

In conclusion, the survey showed that students overall have a positive attitude towards their experience. We suggest that this reflects the assessments students make of the value of what they as individuals get from their participation (whatever that might be for a particular individual). It is also possible that those who are more inclined towards a positive view of the USUs would have been more inclined to complete a survey on their experience; participation bias is extremely difficult to control for in a survey of this nature. Yet the point remains, in responses to the range of questions asked, that those who completed the survey provided an assessment was overwhelmingly positive.

\subsection{Conclusions: the value of the university armed service units for participating students}

The key findings from the survey of students participating in the USUs are as follows.

In terms of the types of students participating in USUs, we would suggest that unit participants are not representative of the UK student body, or even of the Home (that is, UK domiciled) student population. Participating students are more likely to attend a Russell Group university, are more likely to have attended an independent sector school, are more likely to be male and are more likely to be studying particular subjects at university than suggested by national student average figures.

In terms of joining a USU, there is diversity across the three service units in terms of levels of awareness of the existence of USUs prior to arrival at university, and for UAS participants in particular, the availability of a UAS may be a factor in choice of university. Women appear to have lower levels of awareness of USUs prior to university. Freshers' Fairs were a significant source of initial information about the units for $29 \%$ of USU participants overall, and are a more important source of information for women compared to men, and 
for students arriving from state schools than the independent sector. Motivations for joining are a combination of military-specific interests, sporting and adventurous training opportunities, transferable skills suitable for CVs and pay. There are slight differences between men and women in terms of motivations for joining.

In terms of the skills that USU participation helps develop, specifically transferable skills of value to subsequent employment, the USU experience is seen as both providing skills development opportunities across a range of skills, and to an extent that very often exceeds expectations. Assessments of the level that expectations have been exceeded through degree programmes is higher for most cognitive/intellectual skills than for USU participation with the exception of critical thinking, but for communications and interactional skills, expectations are exceeded to a higher degree through USU participation than through degree programmes. There are gender and service unit differences across student assessments of skills development. USU participation is seen as helping positively with degree programme progression by $58 \%$ of USU members.

In terms of careers in the armed forces, a significant proportion had considered a future military career prior to arriving at university. The USU experience appears to be important in shaping student views both with regards to a career in the armed forces, and with regards to potential participation in the Reserves. The experience is also influential in shaping student understanding about wider career options beyond the armed forces.

In terms of employability, $90 \%$ of USU participants thought that being in a USU would help them with getting a job. The transferability of the skills developed through USU participation was seen as the most significant factor in this regard.

In terms of opinions about and perceptions of the armed forces, $92 \%$ overall stated that they had positive opinions about the armed forces, with $15 \%$ of these identifying their views as having changed to a positive assessment as a result of their USU experience. Finally, $90 \%$ of students rated their USU experience as mostly positive. 